\title{
Recent Application of Cellulose Gel in Flexible Sensing-A Review
}

Yixuan Li, ${ }^{1}$ Jing Guo, ${ }^{1}$ Ming Li,${ }^{1}$ Yutong Tang, ${ }^{1}$ Vignesh Murugadoss,${ }^{2}$ Ilwoo Seok,${ }^{3}$ Jingfang Yu, ${ }^{4}$ Luyi Sun, ${ }^{5}$ Caiying Sun ${ }^{1 *}$ and Yangchao Luo $^{6^{*}}$

\begin{abstract}
There is a huge and growing demand for flexible electronics for electronic skin, wearable devices and medical equipment. At the same time, celluloses with the special crystal shape, surface structure, good biocompatibility and easy degradability is frequently used as a substrate or modified substance for flexible electronic equipment. Therefore, the use of cellulose as a raw material is expected to contribute to environmental protection and help to overcome problems such as biocompatibility and stretchability required by flexible sensing devices. The goal of this review is to provide an overview on the latest developments in cellulose gel-based flexible sensors, especially focusing on the detailed descriptions of the major three applications in electronic skin, sports equipment and medical equipment, as well as the relationship between the structure and properties of the cellulose gel material. Finally, an outlook of the challenges and future possibilities for development of flexible sensing equipment based on cellulose gel material is presented.
\end{abstract}

Keywords: Cellulose gel, flexible sensing materials, exercise monitoring, electronic skin.

Received: 24 April 2021; Accepted date: 9 May 2021.

Article type: Review article.

\section{Introduction}

In recent years, due to the development of science and technology, electronic devices are gradually shifting from solid, ordinary and single state that cannot be deformed to high-performance flexible sensing devices that are more suitable for human body design. Electronic skin, wearable electronic products and medical equipment are included in the applications of flexible electronic sensing devices, and

1 College of Chemistry, Chemical Engineering and Resource

Utilization, Northeast Forestry University, Harbin 150040, PR

China.

2 Advanced Materials Division, Engineered Multifunctional

Composites (EMC) Nanotech. LLC, Knoxville, TN 37934 USA.

3 Mechanical Engineering, Arkansas State University, Jonesboro,

Arkansas, 72401 USA.

4 Chemistry Research Laboratory, Department of Chemistry,

University of Oxford, 12 Mansfield Road, Oxford, OX1 3TA, UK.

5 Polymer Program, Institute of Materials Science and Department

of Chemical \& Biomolecular Engineering, University of

Connecticut, Storrs, CT 06269, USA.

6 Department of Nutritional Sciences, University of Connecticut,

Storrs, CT 06269, USA.

*Email: sundeyee@126.com; Yangchao.luo@uconn.edu (Y. Luo) they are all very promising directions..$^{[1,2]}$ Nowadays, many kinds of natural biopolymers have been extracted and characterized by scientists, including chitosan, collagen, silk, gelatin, cellulose, etc., which have broad application prospects in flexible sensing. ${ }^{[3]}$

Generally, better deformability and higher transparency belongs to polycarbonate, polyethylene terephthalate, polyimide, polyethylene, polyurethane and other materials, so they usually used as a traditional flexible sensor substrates. ${ }^{[4]}$ However, another type of traditional flexible substrate, i.e. soft silicone elastomers, such as polydimethylsiloxane (PDMS), ${ }^{[5-}$ ${ }^{7]}$ has better ductility and plasticity than the above-mentioned materials. As a result, such substrates have become the most commonly used material for manufacturing flexible sensor substrate. ${ }^{[8]}$

Flexible sensors with good application value require active sensing elements (high sensitivity requirements and electrical detection methods) and substrates with good tensile deformation ability. However, these requirements cannot be met because of the poor deformation ability of traditional detection elements (such as piezoelectric, capacitive and resistor materials). The research reports on the flexible sensors grow rapidly, and the nanocellulose-based nanofibers with high sensitivity and the synthetic materials made of basic 
materials with relatively good ductility have been among the focal areas, which have already been reviewed extensively. ${ }^{[9]}$

However, with low stretchability of the graphene/PDMS composite strain sensor, the measured structural strain is usually in the range of $0-10 \% \cdot{ }^{[4]}$ When carbon black $(\mathrm{CB})$ with liquid PDMS were mixed, and the resistance change rate $\left(+R / R_{0}\right)$ of the conductive PDMS strain sensor prepared under $80 \%$ of the applied tensile strain was increased from 0 to $150 \% .{ }^{\left[{ }^{[9]}\right.}$ Contrary to PDMS, the higher vertical and horizontal directions and excellent mechanical properties of cellulose can make synthetic materials have better flexibility and tensile properties. The experimental data showed that when graphite and nano-cellulose (NFC) graphite were used together, the tensile strength of the NFC composite material became 1.0 GPa with the toughness of $30.0 \mathrm{MJ} / \mathrm{m} \cdot{ }^{[10]}$ In addition to using cellulose as a basic material, there are also experiments proving that bacterial cellulose (BC) gel can be used instead of graphene to synthesize pyrolysis $\mathrm{BC}(\mathrm{p}-\mathrm{BC}) / \mathrm{PDMS}$. After testing the resistance change rate $\left(+\mathrm{R} / \mathrm{R}_{0}\right)$ of tensile strain from 0 to $80 \%$, the first resistance change only increased from 0 to $14.8 \%$, and the composite material remained conductive until at $118 \%$ strain. Such results demonstrate that the conductivity of pyrolytic $\mathrm{BC}(\mathrm{p}-\mathrm{BC}) / \mathrm{PDMS}$ after stretching is better than the above mentioned liquid PDMS with $\mathrm{CB}$ addition. The cellulose-added material is very suitable for manufacturing flexible sensing devices. ${ }^{[11]}$

Cellulose is the most abundant natural biopolymer, it is found in many plants (Fig. 1), and cellulosic materials are valuable owing to their biodegradability. This advantage makes cellulosic materials suitable for modern green environmental protection. Also, cellulose has good biocompatibility, which is very suitable for manufacturing various medical sensors. Cellulosic materials, as shown by the increasing number of research documents, have promising potential in the development of flexible sensors.

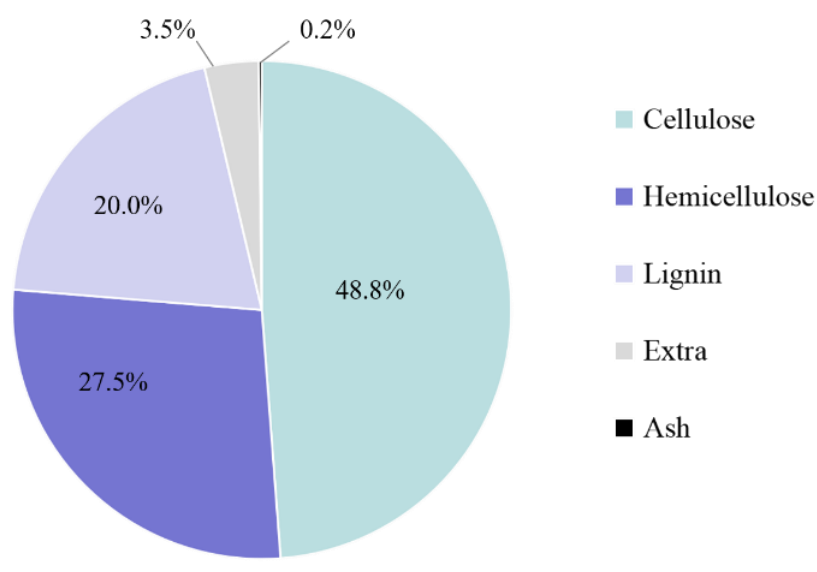

Fig. 1 The proportion of each component (including cellulose, hemicellulose, lignin, other components and ash) in hardwood. Reproduced with permission from [12]. Copyright@Elsevier.

\section{Introduction to Cellulose and Cellulose Gel}

Due to reproducibility and degradability, natural biopolymers have broad application prospects in various flexible devices. Cellulose is a kind of green and renewable resource widely existing in nature, and it is found in many plants and can also be synthesized by certain microorganisms. The nanocellulose, obtained by processing fiber raw materials via chemical, mechanical, enzymatic hydrolysis and other methods, has excellent properties, such as large specific surface area, high aspect ratio, high crystallinity, high transparency, good filmforming properties, and good tensile properties and degradability. ${ }^{[13]}$ Recently, cellulosic materials have attracted great attention to develop environmentally-friendly flexible electronic sensing materials, as already reviewed. ${ }^{[14,15]}$

\subsection{Introduction to cellulose and cellulosic materials 2.1.1 Source of cellulose}

As the most abundant, important green and renewable resource on the earth, cellulose has become one of the most common polymer materials. ${ }^{[16,17]}$ Natural cellulose includes nanocrystalline (CNC), cellulose nanofiber (CNF) and bacterial cellulose (BC) (Fig. 2a). The cellulose content of natural cotton fiber exceeds $98 \%$, and the cellulose content of different types of wood is also maintained between $10 \%$ and $90 \%{ }^{\left[{ }^{3]}\right.}$ In fact, cellulose has been widely used in people's lives since ancient times. For instance, cellulose used in textiles and papermaking has greatly promoted the development of human civilization. Today, commercial cellulose, mainly derived from wood pulp, has become the basis for the production of recycled fibers and films, and for some products, industrialscale production of cellulose derivatives is essential.

\subsubsection{Cellulose structure}

Cellulose is a linear polysaccharide material composed of linear $\beta$-1,4-linked D-glucose units (Fig. 2c), ${ }^{[18]}$ the hydroxyl groups in D-glucose can promote the formation of linear chains through intra-chain and inter-chain hydrogen bond interactions and further enable the orderly accumulation of adjacent chains to form crystalline regions. ${ }^{[19,20]}$ By chemical pretreatment to remove lignin and hemicellulose from plants, purified cellulose in the form of micron-sized cellulose fibers can be obtained. The crystalline regions that have changed the high hardness characteristics of the cellulose material are connected by amorphous regions to form cellulose with many different crystalline states like I, II, III and IV,,$^{[19-21]}$ and the different positions of hydrogen bonds between chains and in chains can be used to distinguish different crystalline cellulose, ${ }^{[22]}$ because of the limited volume, the excellent processability has become the characteristic of this cellulose polymorphic substance, so that cellulose can be further processed into various forms, such as cellulose nanofibers (CNF), cellulose nanocrystals (CNC) and cellulose nanosheets (Fig. 2b). ${ }^{[22]}$ Nanocellulose with high crystallinity and low length-to-diameter ratio is called $\mathrm{CNC}$, while another kind of cellulose $\mathrm{CNF}$, with higher length-to-diameter ratio and lower crystallinity, is usually continuous in amorphous and crystalline regions. As a natural chemical substance with 


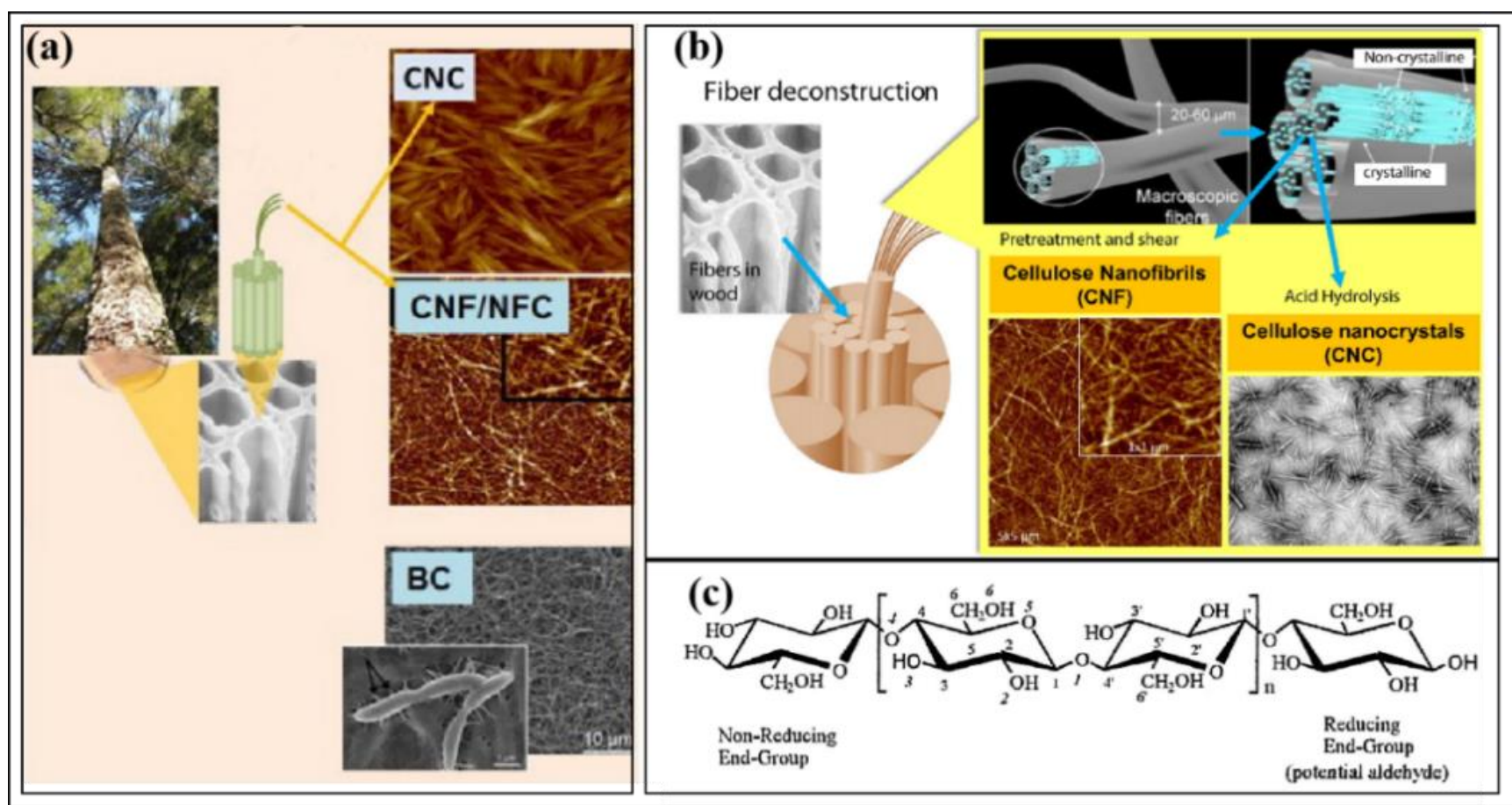

Fig. 2 (a) Schematic diagram of the cellulose source and three natural cellulose including nanocrystals (CNC). Cellulose nanofiber (CNF) and bacterial cellulose (BC). Reproduced with permission from [25]. Copyright@colloid \& interface science. (b) $\mathrm{CNF}$ and $\mathrm{CNC}$ can be produced from the fiber hole wall through mechanical and chemical treatment. Reproduced with permission from [26]. Copyright@Elsevier. (c) Cellulose is a linear biopolymer chain composed of $\beta-(1-4)$ connected dglucose units, end groups and atomic number. Reproduced with permission from [27]. Copyright@ Elsevier.

excellent mechanical properties, stable structure, good thermal stability and good biocompatibility, cellulose can also be processed into different kinds of materials, such as cellulose film, cellulose hydrogel and cellulose aerogels..$^{[23,24]}$ These cellulose-derived materials can also be added with metals or metal oxides to improve their electrical conductivity so that they can be better used in flexible sensing electronic devices. ${ }^{[3,16]}$

\subsubsection{Development of cellulose flexible materials}

Since the first successful separation of cellulose microfibers in $1983,{ }^{[28]}$ cellulose extraction methods have been explored and improved. However, because cellulose is polar and difficult to disperse in non-polar media, different modification processes are needed to overcome the problems caused by its hydrophilicity, such as acetylation, ${ }^{[29,30]}$ silylation $^{[31,32]}$ and other surface modification methods. In order to make cellulose materials better used in actual production and life, various modified substances are added to cellulose nanocomposites, and these composite materials are made into cellulose membranes according to their specific uses, and for flexible sensors cellulose gel is indeed a very good material. ${ }^{[33]}$

\subsection{Brief introduction and application examples of cellulose gel}

\subsubsection{Overview of cellulose hydrogel}

Hydrogel was first invented and defined by Wichterle and Lím in the $1960 \mathrm{~s},{ }^{[34]}$ which is a gel with water as a dispersion medium. The combination of hydrophilic residues and water molecules can connect the water molecules to the cross-linked polymer, where the hydrophilic residues swelling with water can be divided into hydrogels formed from natural polymers and synthetic polymers. The original hydrogel was made by cross-linking synthetic polymers such as polyethylene glycol, ${ }^{[35]}$ polyvinyl alcohol, ${ }^{[36]}$ and it is also favored by researchers in many fields such as food, biological materials, water purification, wound dressing, and electronic sensing. ${ }^{[37-}$ 39] Poly(ethylene glycol) PEG hydrogels alone, however, cannot be used in the human body due to their biological inertness. A number of polysaccharides have similar properties to PEG in terms of biocompatibility and low protein and cell adhesion, and they can be degraded into products that are nontoxic to the human body and easily absorbed. ${ }^{[40]}$

According to the crosslinking method, cellulose hydrogels can be divided into chemical gels made by chemical crosslinking (Fig. 3a) and physical gels made by physical crosslinking. The difference between them is that physical gels are formed by the self-assembly of molecules, ions or hydrogen bonds, while chemical gels are formed by covalent bonds. ${ }^{[41]}$

Generally, CNCs are lack of the ability to entangle with each other to form a mechanically stable hydrogels by themselves due to the small aspect ratio and rigid structure. However, mechanically stable CNCs hydrogels can be obtained by methods such as changing the surface chemical structure ${ }^{[42]}$ or introducing a cross-linked network. ${ }^{[43]}$ In addition, the modified $\mathrm{CNC}$ hydrogel has $\mathrm{pH}$ responsiveness and good biocompatibility, which makes it have great potential 


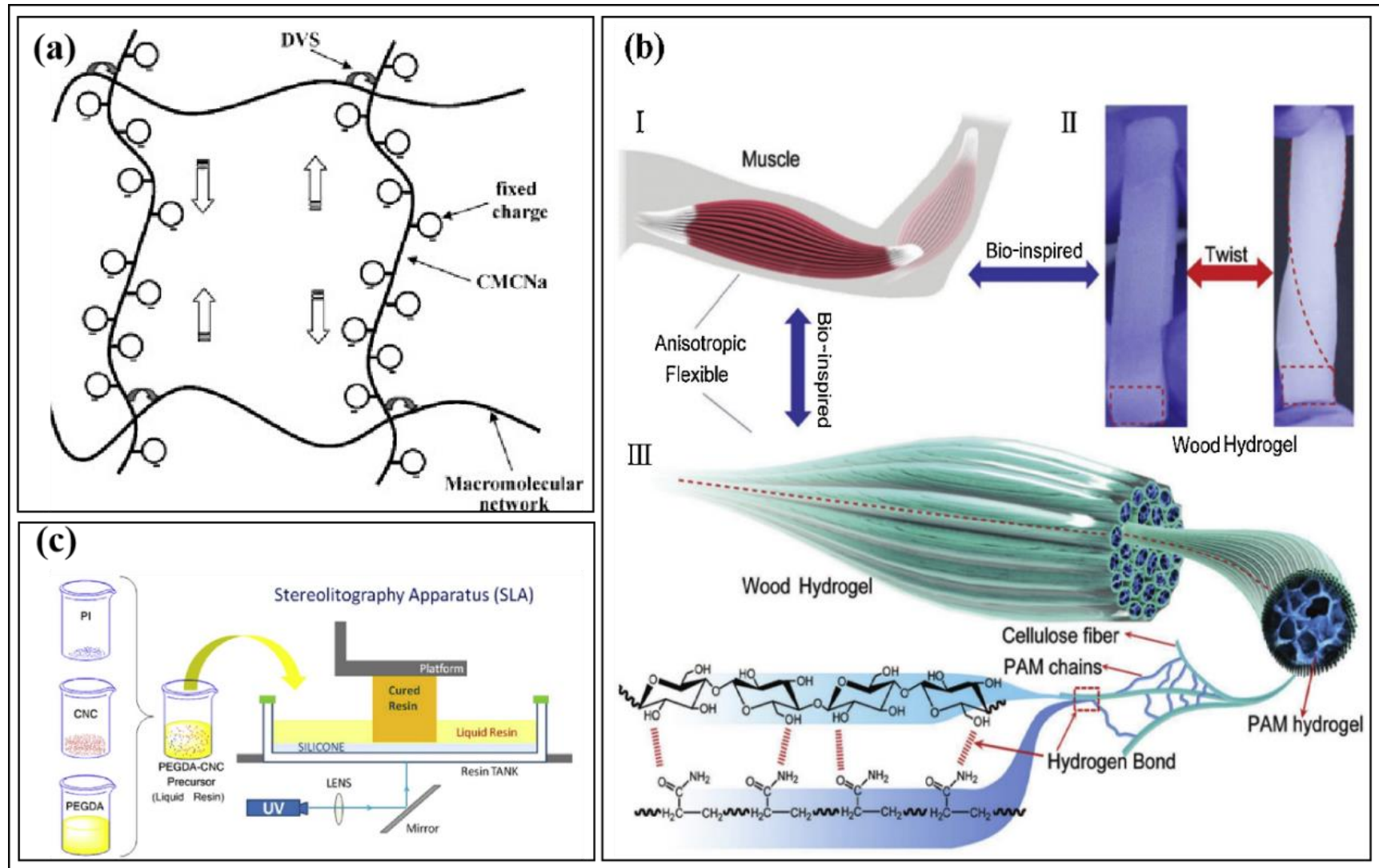

Fig. 3 (a) Through chemical cross-linking, the charged chain acts as a shrinking or expanding device. The big arrow indicates the shrinkage or expansion of the polyelectrolyte chain (Marcì et al., 2006). Reproduced with permission from [40]. Copyright@Elsevier. (b) Application example 1 of cellulose hydrogel (I) Schematic diagram of human skeletal muscle tissue (II) Image of a $7 \mathrm{~cm}$-long wood hydrogel sample distorted by $180^{\circ}$, (III) Description of hydrogen bonding of wood hydrogel and both Covalently cross-linked PAM chains (Kong et al., 2018). Reproduced with permission from [26]. Copyright@Elsevier. (c) Application example of cellulose hydrogel 2. Schematic diagram of the 3D printing system of PEGDA-CNC hydrogel (Palaganas et al., 2017). Reproduced with permission from [26]. Copyright@Elsevier.

in biomedical applications. Similar to CNC, CNF can also be used as a reinforcing agent (filler) to prepare composite hydrogels with excellent mechanical properties. Compared to CNCs, CNFs with high aspect ratio and semi-crystalline structure shows an excellence tendency to form entangling networks, ${ }^{[44]}$ benefiting for the formation of more mechanically stable hydrogels by themselves. Based on the good biocompatibility of cellulose hydrogels, many materials that can be used in medical treatment have been developed. For example, Kong et al. (2018) developed an anisotropic, strong and muscle-like wood hydrogel (Fig. 3b), ${ }^{[45]}$ and experimental data shows that the longitudinal tensile strength of this wood hydrogel is as high as $36 \mathrm{Mpa}$. In addition, CNC and $\mathrm{CNF}$ gels can also be used in combination with 3D printing technology to make different types of more flexible materials (Fig. 3c). ${ }^{[46-48]}$

\subsubsection{Overview of cellulose aerogel}

In the early 1930s, Kistler first developed an aerogel that used supercritical drying ${ }^{[49]}$ to remove the liquid in the wet gel. In the past few decades, inorganic aerogels (such as silica aerogels ${ }^{[50]}$ ) first appeared. However, the mechanical properties of silica aerogels are very poor ${ }^{[51]}$ and the body is toxic and non-degradable, and its high preparation cost greatly limits the application of aerogels. Later, synthetic polymerbased aerogels, natural macromolecular aerogels and carbon aerogels have solved this problem, among which the cellulose aerogel has become a very good material. Cellulose aerogel has other advantages of cellulose biocompatibility, biodegradability, ${ }^{[52]}$ low density, high porosity and large specific surface area, and has a very broad applications in different fields. ${ }^{[53]}$ Cellulose aerogels are usually divided into three steps: dissolving/dispersing cellulose, forming a cellulose gel through a sol process, and finally drying the cellulose gel while essentially maintaining its $3 \mathrm{D}$ porous structure, ${ }^{[54]}$ among which the sol reaction is the most critical step to form a 3D porous network structure in the aerogel. Aerogel preparation process does not need crosslinking agent, meaning that cellulose can be physically cross-linked to obtain a stable three-dimensional network structure, forming aerogel. ${ }^{[5]}$ The preparation method of cellulose aerogel and the properties of corresponding materials are closely related to the purity of cellulose. ${ }^{[56,57]}$ Therefore, according to different cellulose raw materials and synthesis methods, cellulose aerogels can be divided into three categories: (1) Natural cellulose aerogels (including nano-cellulose aerogels Gel, ${ }^{[58]}$ 


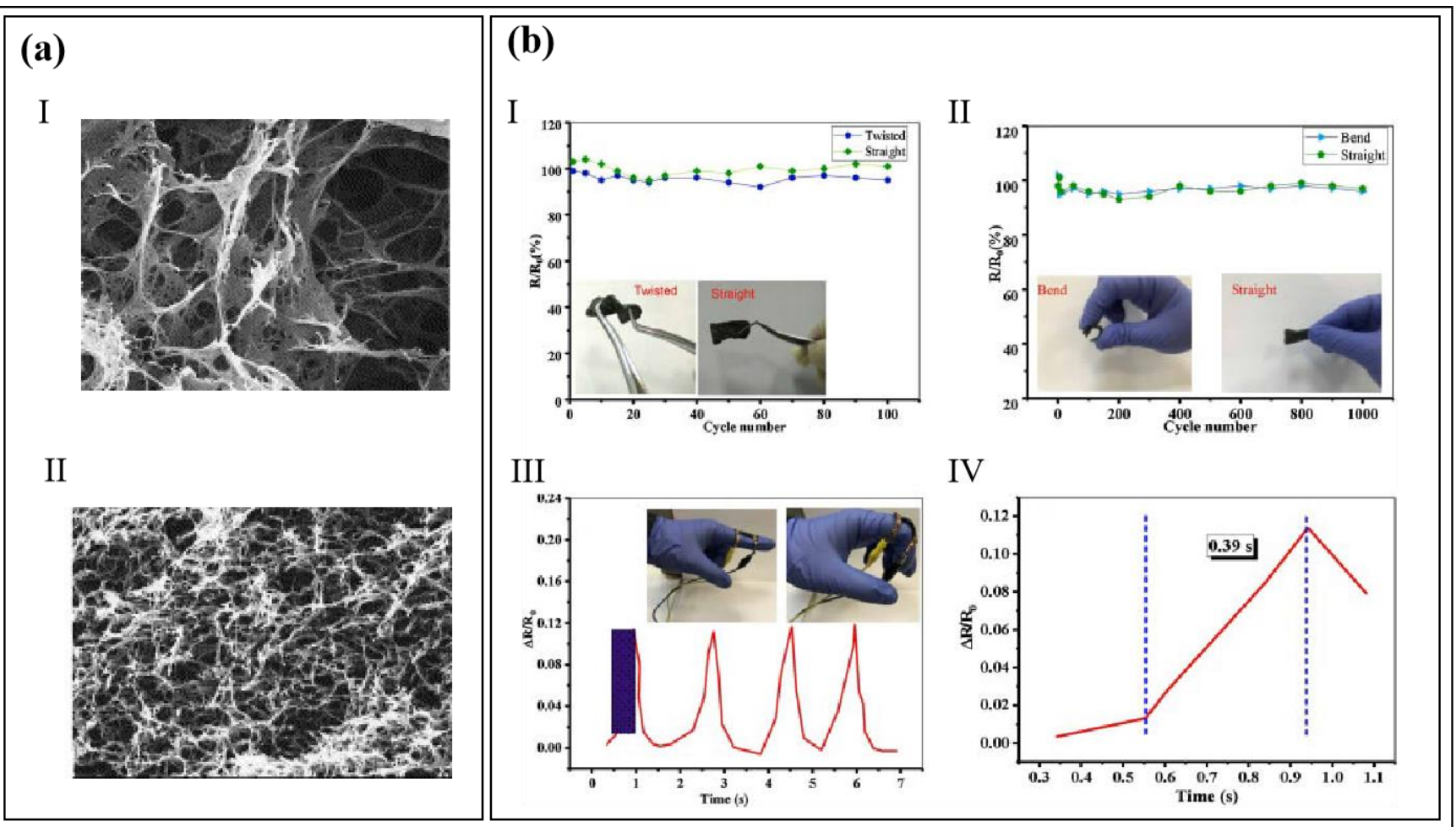

Fig. 4 (a)Microscopic morphology of conventional freeze-dried aerogel. I 0.5\%; II 3.0\%. Reproduced with permission from [64]. Copyright@Elsevier.(b)Flexibility tests: resistance over 100 cycles in torsion mode I. and II. over 1000 cycles in tension mode (insert: photo of the unloading state of BC/MWCNTs nano-synthetic aerogel), III. relative resistivity changes during finger bending, and IV. response time for fabrication of sensors. Reproduced with permission from [63]. Copyright@Elsevier.

bacterial cellulose aerogel $\left.{ }^{[59]}\right)$, (2) regenerated cellulose aerogel, (3) cellulose derivative aerogels. ${ }^{[60]}$ The first type of natural cellulose gel is made of cellulose nanofibers and/or cellulose nanocrystals $(\mathrm{CNC})$. To make a cellulose gel, first, it is necessary to use a solvent to break the hydrogen bonds in the natural cellulose, so that after dissolution, the cellulose is directly prepared, and then the cellulose is regenerated to for a gel with the help of a coagulation bath. ${ }^{[5,61]}$

The focus of the preparation of cellulose aerogel is to protect the network structure (folding pore structure), so the drying step that may destroy the structure of the cellulose aerogel also requires our attention. Recent studies have found two gel drying methods, i.e., freeze drying (Fig. 4a) and supercritical drying, ${ }^{[55,62]}$ that are applicable to produce cellulose aerogel, among which the supercritical drying process has higher complexity and equipment cost. Adding modified substances (such as multi-walled carbon nanotubes, etc.) to cellulose aerogels can make it better used in flexible sensing technologies, such as the in-situ biosynthetic bacterial cellulose (BC) prepared by Hadi Hosseini et al. Multi-walled carbon nanotube (MWCNT) nanocomposite aerogel is suitable for manufacturing strain sensors to monitor human motion detection (Fig. 4b). ${ }^{[63]}$

\section{Application of cellulose gel in flexible sensing}

Nowadays, as human beings are paying more attention to physical health, large and expensive medical equipment and their cumbersome usability not only increase the cost of health monitoring, but also bring a lot of anxiety and pain to patients. In the 21 st century, we hope to have easy access to various physiological data, sensing equipment is thus critically needed in various parts of the body to monitor our health and provide data. However, traditional sensors of metal or semiconductor cannot meet the needs of the human body due to their rigidity and brittleness. ${ }^{[65]}$ Because of this, the industry and academia have developed a strong interest in flexible sensors, and scientists have begun to improve their mechanical properties, including tensile properties, deformation properties, and biocompatibility, so that they can be used in various parts of the human body. ${ }^{[66]}$ Due to the flexibility, extensibility and mechanical strength of cellulose hydrogels, it has become an ideal substrate for motion conduction. ${ }^{[67]}$ For cellulose aerogels, porous aerogel materials have low density, high sensitivity and good mechanical properties. Such advantages lead to it being able to detect deformation very sensitively, so researchers combine conductive materials with cellulose to form aerogels and apply them to motion signal detection. The biocompatibility and adhesion of cellulose hydrogel and cellulose aerogel also meet the comfort requirements of the human body for flexible sensors, ${ }^{[68]}$ so more and more cellulose gels are made of materials. The following is an overview of the development of cellulose gel materials in the three applications of electronic skin, sports equipment and medical equipment.

\subsection{Electronic skin}


As mentioned above, cellulose, as the most abundant natural polymer in nature, is biodegradable, biocompatible and environmental friendliness, and it has many attractive and advantageous properties, including mechanical, dielectric, piezoelectric and switching properties. Cellulose has attracted keen interest for flexible sensing field adhesives, dielectric layers, gel electrolytes and derived carbon materials. ${ }^{[69-71]}$

Cellulose can be widely used as a basic material for manufacturing various functional materials (piezoelectric membranes, bionic skin and tissue regions) due to its easy processing and integration characteristics. ${ }^{[72]}$ The various advantages of cellulose-based materials are of great significance to the birth of portable intelligent electronic product design, and have broad prospects in the application of flexible electronic devices, mainly reflected in mobile devices, human-machine interface units, wearable medical systems and bionics Learn flexible electronic products, smart robots, electronic skins, etc. ${ }^{[73-76]}$

Electronic skin (also known as a new wearable flexible bionic tactile sensor) which uses flexible electronic technology to manufacture electronic devices that function similar to human skin is one of them. ${ }^{[77]}$ Due to the similarity with biological skin functions, especially its excellent mechanical properties and sensitivity, it can be sensed in slight environmental differences (pressure, strain, temperature, humidity), and this series of gel materials can be flexibly applied on the field of artificial intelligence. ${ }^{[78]}$ Although the development of electronic skin has achieved certain progress, its sensitivity to external stimuli, self-repair, mechanical flexibility and biocompatibility still needs further development, improvement and optimization. ${ }^{[79,80]}$

Inspired by the rapid migration of ions between epidermal neurons in human skin, the electronic skins are usually made to be very sensitive to changes in the external environment (temperature, humidity, vibration and touch). ${ }^{[81,82]}$ Zhao et al. successfully developed a cellulose-based electronic skin containing only cellulose, ${ }^{[83]}$ ions and $\mathrm{H}_{2} \mathrm{O}$, accompanied by an excellent ability to perceive changes in the external environment. ${ }^{[84]}$ As shown in Fig. 5a, the bio mimetic electronic skin made of cellulose ion hydrogel (Cel-IL dynamic gel) is driven by a dynamic hydrogen bond network based on humidity and reversible microstructure, thereby achieving better ductility, firmness and flexibility. The results are shown in Fig. 5b. It can be seamlessly pasted on human skin and is easy to remove, thus reducing pain and not damaging the skin tissue. According to the results shown in Fig. $5 \mathrm{c}$, the bionic electronic skin can respond to changes in the external environment, airflow signals and health status (quiet, nervous, irritable) in a timely manner. This electronic skin's excellent ability to perceive environmental changes, as well as excellent ductility, firmness and flexibility, is expected to be widely used in the field of life. However, it should be noted that since the bionic skin needs to imitate the various characteristics of human skin (mechanical and sensory characteristics), it also demands to respond in time to changes in external stimuli. ${ }^{[85]}$ In addition to having sufficient sensitivity, it needs to have strong mechanical properties, high self-repair properties, high biocompatibility and ultrasensitive properties. The advantages and applications are summarized in (Table 1), and the preparation of gel materials with various properties should be the major development direction in the future. ${ }^{[86]}$

In addition to hydrogels, aerogels are highly porous solids that can hold gas (usually air) in the pores or network of solid materials. Because of its light weight, low thermal conductivity and large internal surface area, it has attracted great attention to use as electronic equipment. ${ }^{[87]}$ The wellknown aerogel is an inorganic aerogel of silica and metal oxides. However, these inorganic aerogels generally have low mechanical strength and tend to collapse when subjected to small stresses. In contrast, aerogels made of organic polymers can be mechanically stable. ${ }^{[88,89]}$

Cai et al. prepared a highly porous and strong cellulose aerogel by gelling cellulose from an aqueous alkali metal hydroxide/urea solution and then dried it with supercritical $\mathrm{CO}_{2}{ }^{\left[{ }^{90]}\right.}$ The cellulose hydrogel is composed of interconnected fibrils approximately $20 \mathrm{~nm}$ wide. Based on the difference between the loose aggregates of inter molecularly associated silica nanoparticles and the cellulose fiber network, the network structure in the hydrogel can be well retained in the aerogel upon drying by supercritical $\mathrm{CO}_{2}$. The fracture stress of cellulose aerogels ranges from 10 to $20 \mathrm{MPa}$, which is very impressive for materials with a porosity of $80-90 \%$. The typical value of Young's modulus is $200-300 \mathrm{MPa}$, which is two orders of magnitude larger than inorganic silica aerogel (about $1 \mathrm{MPa}$ ). With this high mechanical performance, it can be widely used to prepare highly porous and mechanically stable cellulose aerogel.

Shao et al. further prepared a conductive hydrogel material with dynamic self-adhesiveness, high incompatibility and self-healing ability. ${ }^{[91]}$ The double-cross-linked gel network is combined through reversible hydrogen bonding and electrostatic interaction, making this material show excellent mechanical properties (strain $>700 \%$ ), reliable self-repair ability (HE $>90 \%$ ) and strong adhesion (similar to $440 \mathrm{~N} \cdot \mathrm{m}$ $(-1)$ ), easy separation in water and improved biocompatibility to provide an idea for the formation of an integrated electronic skin with high sensory characteristics. ${ }^{[87]}$ The advantages and applications of conductive hydrogel are summarized in Table 1.

Based on the above ideas and the design principle of the hydrogen bond topology network, in addition to hydrogels and aerogels, ionic gel materials of cellulose, ionic liquid and water (CEL-IL dynamic gels, which have good ductility, toughness, high ionic conductivity, strong adhesion, fast repair), has broad application prospects in the field of electronic skin and artificial intelligence. ${ }^{[92,93]}$ By adding graphene (GN) and polyvinyl alcohol-borax (GN-CNF@PVA) to the mixed cellulose nanofibers (CNFS), borax is used as a cross-linking agent to combine polyvinyl alcohol (PVA) and 


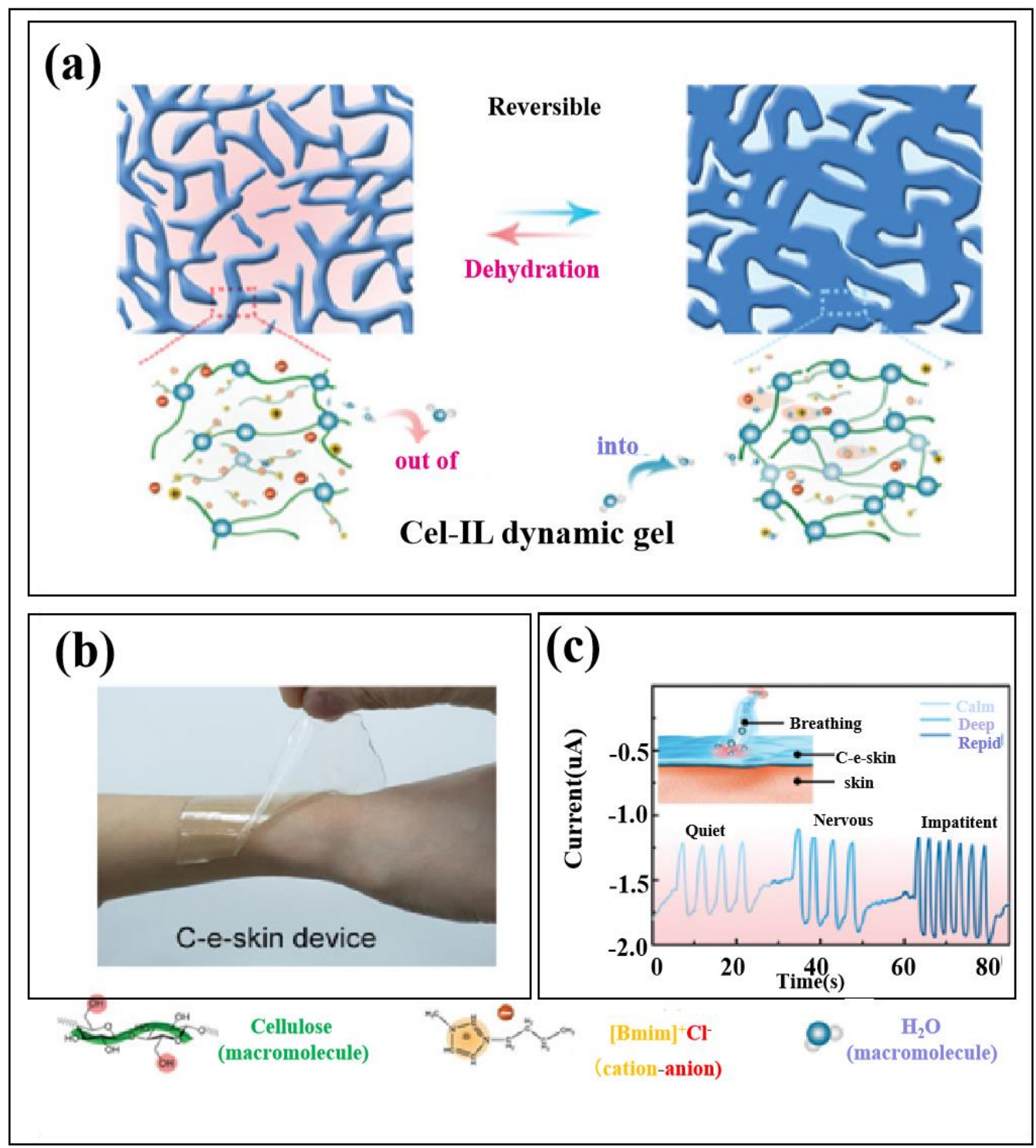

Fig. 5 (a) The design and function of the interaction process of the reversible dynamic hydrogen bond topology tunable cellulose ion hydrogel (Cel-IL dynamic gel). (b) The bionic electronic skin prepared by Cel-IL dynamic gel has excellent adhesion and is easy to remove. (c) The respiratory signal sensed by Cel-IL electronic skin respectively corresponds to the signal of quiet, nervous, and impatience. Reproduced with permission from [83]. Copyright@Elsevier.

GN-Combine CNF together. This composite gel dynamically provides a flexible and strong network for the hydrogel, and at the same time has high tensile properties (up to $1000 \%$ elongation at break), excellent viscoelasticity (up to $3.7 \mathrm{kPa}$ storage modulus), and rapid Self-healing ability (20s) and high healing efficiency $(97.7 \pm 1.2 \%)$. This material with strong adhesion, high self-repair and strong mechanical properties not only has broad application prospects in the field of electronic skin, but also exerts huge application potential in the field of wearable sensor equipment and medical treatment. ${ }^{[94]}$

In recent years, although certain progress has been made in the preparation of conductive self-healing hydrogels with similar biological skin functions, the preparation of integrated materials with strong mechanical properties, excellent selfhealing properties, and highly sensitive to electrical conductivity and strain is still a huge challenge. ${ }^{[95]}$ Shao et al. used cellulose nanocrystals to establish multi-coordination bonds between poly acrylic acid chains and metal ions, thereby designing an ionic coagulation colloid with toughness, self-healing and self-healing system, which has reliable mechanical properties and self-healing properties. ${ }^{[96]}$ It can directly adhere to human skin without being affected by external stimuli, and there are no adverse reactions when using. ${ }^{[97]}$ In order to test the self-healing ability, the relevant data are summarized in Figs. 6a-6d. As shown in the Fig. 6a, the sample was cut into two parts and placed in an airtight container. It can be found that the sample can heal automatically without applying external force or other stimuli, and even if the self-healing ionic gel is in a stretched state, it will not be destroyed at the healing interface. This obviously shows the excellent self-healing ability and strong mechanical properties. The relationship between the healing time and the fracture stress of the healed ionic gel is shown in Fig. 6b, and 
the healing efficiency (HE) was evaluated to reflect its excellent self-healing performance. In addition, the increase in (TA@CN) content can effectively improve the self-healing efficiency of the ionic gel within 30 mins of the healing time, and its mechanical properties and self-healing ability are still at a high level, as shown in Fig. 6c. Next, the microscopic selfrepairing behavior of ionic gel is further proved. The results are shown in Fig. 6d, the rapid transformation of the surface sol-gel confirms the excellent self-repairing ability of the ionic gel, which is attributed to the reconstruction of the reversible ion coordination complex in the gel network system. It has attracted people's attention that the self-repairing behavior of this ionic gel can occur automatically without any external intervention, so it is an ideal choice for extension to practical applications.

Inspired by the mechanically superior and self-healing biological soft tissue with a layered network structure, Liu et $a l .{ }^{[98]}$ prepared a functional network hydrogel, which combines a "soft" homogeneous polymer network with a "hard" dynamic trivalent iron $\left(\mathrm{Fe}^{3+}\right)\left(\mathrm{CNCs}-\mathrm{Fe}^{3+}\right)$ network made by interconnecting cross-linked cellulose nanocrystals. Under such a network system, $\mathrm{CNCs}-\mathrm{Fe}^{3+}$ coordination bonds can effectively dissipate energy, and a uniform polymer network structure can achieve smooth stress transfer. With this structure, the hydrogel has excellent mechanical properties, strong toughness, stretch ability and good self-healing properties at the same time. This hydrogel only takes 5 mins to show autonomous self-healing ability without any stimulus or therapeutic agent. After the hydrogel has been subjected to high-strength deformation tests of compression and knotting, there is no observable damage. In addition, the sample can be easily applied to various free-form deformations, which fully demonstrates its excellent resilience. The results are shown in Figs. 7a and 7b. More importantly, this material is also suitable for uneven deformation. In Fig. 7c, after the sample stretching to $900 \%$ of the surface extension under biaxial stretching, or when strong pressure is applied to the center of the sample by a metal cylinder, the sample can withstand uneven deformation without breaking. It can be seen from the phenomenon in Fig. 7d, the hydrogel is tightly attached to the human skin, and will not detach from the human skin with the movement of the joints, and has good stretch ability. This
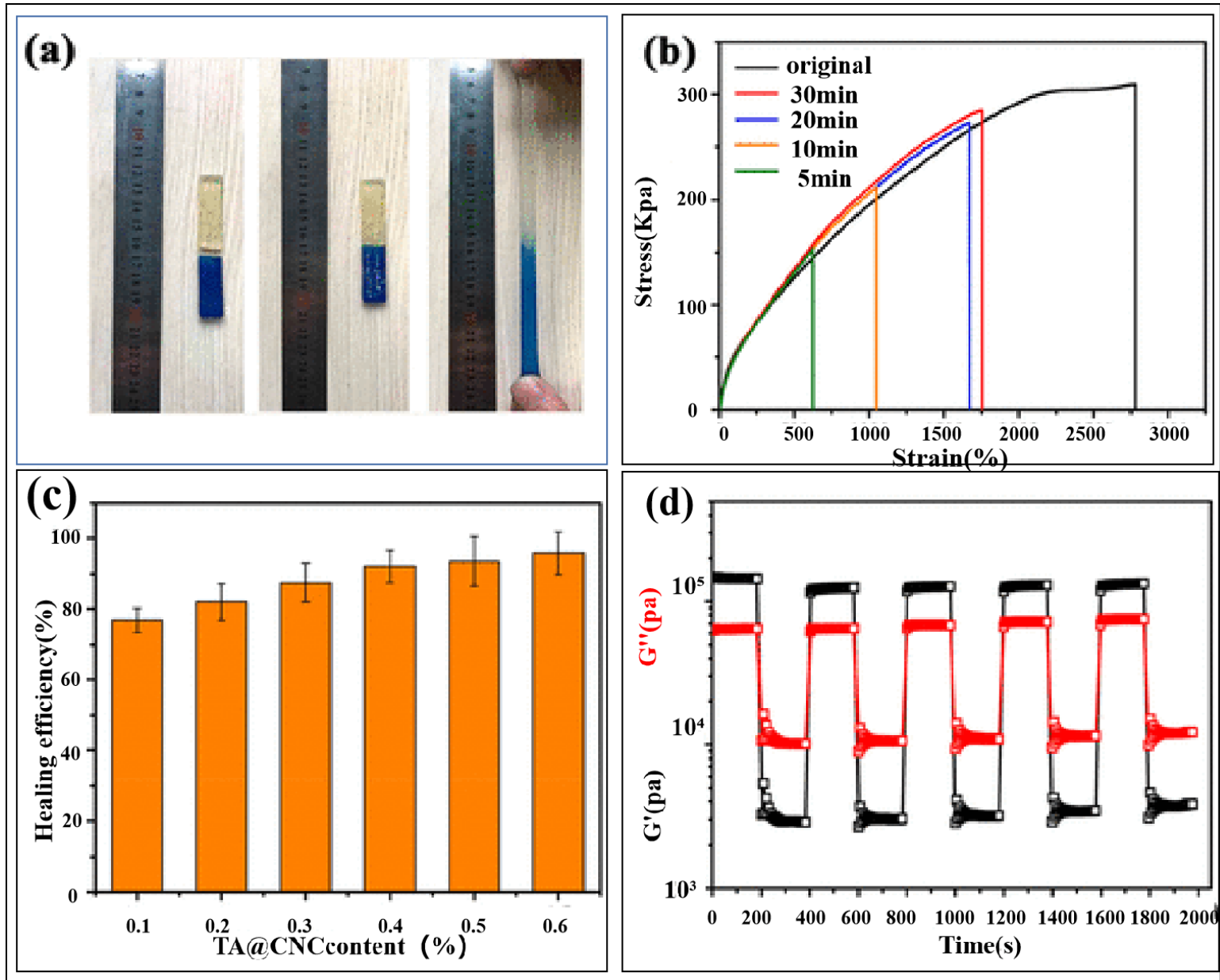

Fig. 6 The self-healing performance of TA@CNC ionic gel at $25^{\circ} \mathrm{C}$. (a) The ionic gel was cut into two sections, the broken gel can be repaired automatically, and it will remain stretched after 30 mins of healing without breaking. (b) Compared the typical stress-strain curves of original and self-healing (TA@CNC)-0.8 ionic gels with different healing times are shown. (c) The relationship between the healing efficiency of ionic gel and the content of TA@CNC after 30 mins of healing is shown. (d) With 200s as a fixed time interval, the G' and G" of TA@CNC-0.8 ionic gel was tested in alternate steps with strain=1 and 100\%. Reproduced with permission from [91]. Copyright@American Chemical Society. 
potential is proven in sensor applications that can be worn on the human body.

In order to further prepare materials that encapsulate the above-mentioned various types of excellent properties, as well as a high degree of light transmittance. Xin et al. synthesized a polyvinyl alcohol/cellulose nanofiber (PVA/CNF) hydrogel with a double cross-linked network, ${ }^{\left[{ }^{[9]}\right.}$ which can be used for highly transparent, stretchable, self-healing pressure and strain sensors. Compared with traditional PVA hydrogel, PVA/CNF hydrogel has better performance stability, stronger mechanical strength band and more timely spontaneous self-healing ability. ${ }^{[100]}$ It has a moderate modulus, an elastic modulus of $11.2 \mathrm{KPa}$ and an elongation of $1900 \%$. It has good biocompatibility with human fibroblasts and can heal quickly and spontaneously within $15 \mathrm{sec}$ without being affected by external stimuli, and the light transmittance is greater than $90 \%$. There is no doubt that this will show great potential in sensors, electronic skins, wearable devices and personal healthcare. Based on its strong light transmittance, it can also provide a basis for the development of synthetic irritant and transparent smart skin sensors. ${ }^{[101]}$

After years of research, the mechanical properties, selfhealing properties, biocompatibility and self-adhesive properties of cellulose gel materials have been well improved. ${ }^{[102,103]}$ Various advantages based on cellulose gel can be widely used in electronic skin, motion detection, medical and other fields. However, whether this material can be used normally under special conditions (low temperature) and whether its use under abnormal conditions is affected is still worthy of further discussion. ${ }^{[104-106]}$ The various properties, advantages and application comparisons of cellulose gels are summarized in Table 1.

\subsection{Wearable device}

A wearable device is a portable device that is directly worn on the body or integrated into the user's clothes or accessories. Wearable devices are not only a hardware device, but also realize powerful functions through software support, data interaction, and cloud interaction. When promoting intimate communication between people and devices, the humanmachine interface (HMI) is the medium for interaction and information exchange between the system and the user. Humans are designing hardware for the HMI of wearable devices. Because human skin is soft and stretchable, the materials used will undergo various forms of deformation like the human body-bending, folding, twisting and stretching. Many electronic devices used in medical treatment have been developed into flexible wearable. ${ }^{[68,107-115]}$ Although cellulose hydrogel has made great progress in the electronic field of wearable devices, the differences between humans and metal or semiconductor devices cannot meet the diverse needs of biological applications. For example, metals and semiconductors are inherently poorly flexible and cannot be stretched. Secondly, the difference in signal carriers between the two makes it impossible to promote direct communication between electronic devices and living beings, therefore, flexible, conductive, and stretchable materials have recently attracted attention.

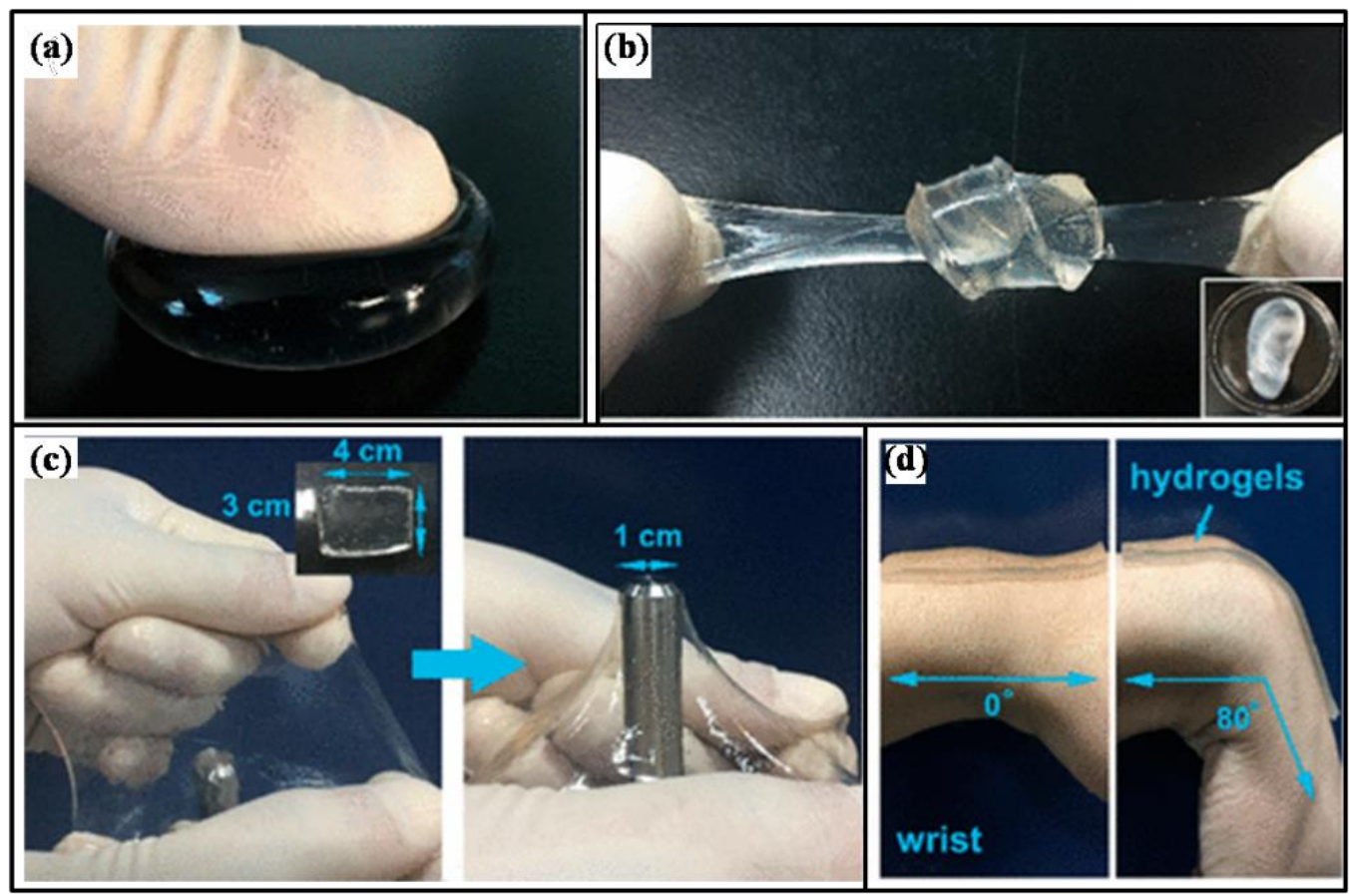

Fig. 7 The remarkable toughness of F-hydrogel-15/2.5. (a) There is no rupture under strong pressure; (b) Stretching and knotting. (Illustration: Artificial ear cartilage is made of F-hydrogel 15/2.5.) (c) A rectangular sample is shown a $900 \%$ surface expansion under biaxial stretching, and when a metal cylinder (diameter $=1 \mathrm{~cm}$ ) pokes the sample center of. (Inset: The size of the original rectangular sample is $4 \times 3 \times 0.2 \mathrm{~cm}^{3}$, and the area expansion is $12 \times 9 \mathrm{~cm}^{2}$ ). (d) The hydrogel is adhered closely to the skin surface (wrist curvature ranges from $0^{\circ}$ to $80^{\circ}$ ). Reproduced with permission from [98]. Copyright@American Chemical Society. 
Table 1. Performance, advantages and application comparison of cellulose gel.

\begin{tabular}{|c|c|c|c|c|c|}
\hline Material & Self-healing & Mechanical behavior & Advantage & Application & Origins \\
\hline $\begin{array}{l}\text { Cellulose ion } \\
\text { hydrogel }\end{array}$ & - & - & Firmness, flexibility & Responder & {$[82]$} \\
\hline Cellulose serogel & - & $\begin{array}{l}10-20 \mathrm{MPa} \text { (Breaking } \\
\text { stress) } \\
200-300 \quad \mathrm{MPa} \\
\text { (Young's modulus) }\end{array}$ & $\begin{array}{l}\text { Excellent mechanical } \\
\text { properties }\end{array}$ & $\begin{array}{l}\text { Electronic } \\
\text { skin sensor }\end{array}$ & {$[90]$} \\
\hline $\begin{array}{l}\text { Cellulose } \\
\text { conductive } \\
\text { hydrogel material }\end{array}$ & $\mathrm{HE}>90 \%$ & Strain $>700 \%$ & High biocompatibility & $\begin{array}{l}\text { Integrated } \\
\text { electronic skin }\end{array}$ & [91] \\
\hline $\begin{array}{l}\text { Cellulose } \\
\text { composite } \\
\text { hydrogel }\end{array}$ & $\begin{array}{l}\text { HE }(-97.7 \%) \\
\text { self-healing } \\
\text { (20s) }\end{array}$ & $\begin{array}{l}11.2 \mathrm{KPa} \text { (Elasticity } \\
\text { modulus) }\end{array}$ & $\begin{array}{l}\text { Flexible and high } \\
\text { overall performance }\end{array}$ & $\begin{array}{l}\text { Wearable } \\
\text { sensor device }\end{array}$ & [91] \\
\hline $\begin{array}{l}\text { Functional } \\
\text { network hydrogel }\end{array}$ & (-1) - + & - & $\begin{array}{l}\text { Excellent mechanical } \\
\text { properties, } \\
\text { stretchability }\end{array}$ & $\begin{array}{l}\text { Flexible } \\
\text { sensing field }\end{array}$ & {$[98]$} \\
\hline $\begin{array}{l}(\mathrm{PVA} / \mathrm{CNF}) \\
\text { Hydrogel }\end{array}$ & $\begin{array}{l}\text { Self-healing } \\
\text { ability (15 s) }\end{array}$ & $\begin{array}{l}11.2 \mathrm{kPa} \text { (Elasticity } \\
\text { modulus) }\end{array}$ & $\begin{array}{l}\text { Highly transparent, } \\
\text { self-healing }\end{array}$ & $\begin{array}{l}\text { Transparent } \\
\text { smart skin } \\
\text { sensor }\end{array}$ & [99] \\
\hline
\end{tabular}

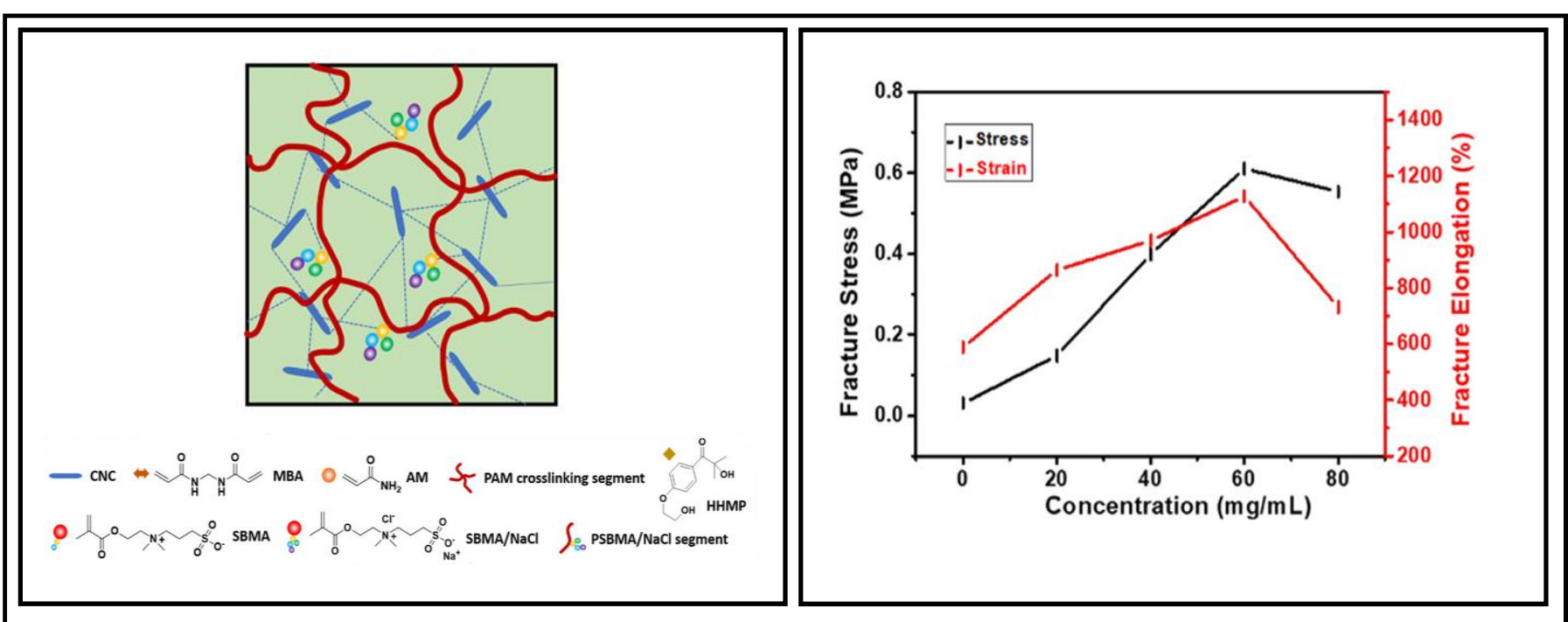

Fig. 8 (a) Scheme of the synthetic of CNC@P(SBMA-co-AM) zwitterionic nanocomposite hydrogels. (b) Fracture tensile strength and elongation, the fracture tensile strain attained a maximum value of $1127 \%$ at a concentration of $60 \mathrm{mg} / \mathrm{ml}$. Reproduced with permission from [119]. Copyright@American Chemical Society.

3.2.1Application of cellulose hydrogel in wearable devices After years of research and exploration of hydrogel materials, researchers can make hydrogel materials have high mechanical properties and adhesion properties at the same time. ${ }^{[116-118]}$ Exceptional mechanical properties ensure that the hydrogel material remains intact under external force, and the adhesive properties can make it adhere closely to the skin. In addition, it can also give the hydrogel self-healing properties to extend the service life of electronic devices and reduce their maintenance costs.

Because conventional hydrogels are soft but fragile and are not suitable for wearable devices, the mechanical properties of hydrogels had been improved in the past few years. Artificial skin-like stretchable ion sensor devices usually require reliable adhesion between man-machine interfaces, reasonable mechanical strength and visually displayable transparency. Through the research of Yang and Yuan, ${ }^{[119]}$ in the presence of cellulose nanocrystals as a physical cross-linking agent and enhancer, a plant-inspired zwitterionic hydrogels were prepared by rapid ultraviolet initiation (Fig. 8a). The resulting transparent zwitterionic nanocomposite hydrogels have successfully brought a variety of advantages, such as strong bonding strength between skin, plastic, glass and steel. Such hydrogel has significant mechanical properties and can be stretched more than $1000 \%$ strain (Fig. 8b). The mechanical tensile strength is as high as $0.61 \mathrm{MPa}$, and the compressive strength is as high as $7.5 \mathrm{MPa}$, and they have excellent ion transport properties. In addition, zwitterionic nanocomposite hydrogels are made into wearable, stretchable and stretchable pressure strain sensors for skin patches that are sensitive to human movement. Such hydrogels maintain compression cycle sensitivity at different pressures of $0.5,1.0$, and $1.5 \mathrm{~Hz}$. Multifunctional zwitterionic nanocomposite hydrogels can also be assembled into flexible electronic devices, such as light-emitting displays and mechanical sensing electronic devices, to realize information transmission and artificial 
intelligence between humans and robots. ${ }^{[119]}$

Because wearable devices require materials with high mechanical and tensile properties, Jing ${ }^{[120]}$ made the polyvinyl alcohol/cellulose nanofibril (PVA/CNF) hydrogel, the mechanical properties and stretching rate of which surpassed that of CNC@P(SBMA-co-AM). The as-prepared hydrogel also had high transparency and self-healing properties. In this work, Jing ${ }^{[120]}$ et al. synthesized a PVA/CNF hydrogel with a double cross-linked network to realize a highly transparent, stretchable and self-healing pressure and strain sensor (Fig. 9a). The hydrogel contains dynamic borate bonds, metal carboxylate coordination bonds and hydrogen bonds. Compared with traditional PVA hydrogels, they all have excellent dimensional stability, mechanical strength and flexibility, and spontaneous self-healing ability. The developed hydrogel has a moderate $11.2 \mathrm{KPa}$ modulus and a high elongation of $1900 \%$ (Fig. 9b). It can heal spontaneously within $15 \mathrm{~s}$ after contact without any external stimulation, showing a light transmittance of more than $90 \%$ and excellent compatibility with human fibroblasts. Capacitive sensors based on PVA/CNF hydrogel has high sensitivity to very subtle pressure changes (such as small water droplets). When used as a strain sensor, it can detect and monitor various human movements, such as finger, knee, elbow and head movements, breathing and tapping. ${ }^{[120]}$

On this basis, Wang ${ }^{[121]}$ et al. made a hydrogel with better mechanical strength and tensile properties than the previous two. In addition, it can withstand harsh conditions such as bending, folding, poking, washing, immersion, and underwater use. The stable hydrogel electrolyte is made by coupling the graft copolymer xanthan gum-polyacrylamide (XG-PAM) and cotton cellulose nanofibers (CNF), denoted as XG-PAM/CNF (Fig. 10a). The designed XG-PAM/CNF hydrogel electrolyte has high ionic conductivity $\left(28.8 \mathrm{mScm}^{-}\right.$ ${ }^{1}$ ), good adhesion, high mechanical strength and strong ion adsorption capacity. More interestingly, the prepared XG-
$\mathrm{PAM} / \mathrm{CNF}$ has good tensile strength $(84 \mathrm{kPa})$ and high stretchability, being able to stretch to $2070 \%$ strain (Fig. 10b). The flexible Zn-ion batteries (ZIBs) with XG-PAM/CNF hydrogel electrolyte has high specific capacity $\left(237 \mathrm{~mA} \cdot \mathrm{h} \cdot \mathrm{g}^{-1}\right)$ and excellent cycle stability $(86.2 \%$ retention in 1000 cycles at $4 \mathrm{C}$ ). It is worth noting that the flexible ZIBs can withstand harsh conditions such as bending, folding, poking, washing, immersion and use under water. Compared the above three modification methods, it is concluded that XG-PAM/CNF is the best (Table 2). In addition, the application of underwater early warning and rescue system is also proposed. Therefore, this work provides new methods and applications for the development of reliable and durable wearable energy storage devices. ${ }^{[121]}$

\subsubsection{Application of cellulose aerogel in wearable devices}

In recent years, researchers have synthesized a series of lowdensity, high-porosity elastic carbon aerogels using carbon nanomaterials such as graphene, graphene oxide (GO), carbon nanotubes (CNT) and their composites. These carbon aerogels have good mechanical stability, elasticity and high conductivity, showing their important applications in wearable sensors, electronic skins and flexible energy storage devices. ${ }^{[122-126]}$

The ultra-light cellulose fiber/thermal reduced graphene oxide $(\mathrm{CF} / \mathrm{RGO})$ hybrid aerogel prepared by $\mathrm{Wan}^{[127]}$ et al. through freeze-drying and carbonization processes has super elasticity and excellent electromagnetic interference (EMI) shielding capabilities. The CF/RGO aerogel with a thickness of $5 \mathrm{~mm}$ has a high EMI shielding effect (SE) of about 47.8 $\mathrm{dB}$ after annealing at $200{ }^{\circ} \mathrm{C}$ in a $5 \%$ hydrogen-argon mixed atmosphere. The excellent SE is mainly due to the pore structure of the aerogel and good conductivity. The density of $\mathrm{CF} / \mathrm{RGO}$ aerogel is as low as $2.83 \mathrm{mg} / \mathrm{cm}^{3}$, and it has an ultrahigh specific shielding effect (up to $33780 \mathrm{~dB} \mathrm{~cm} / \mathrm{g}$ ). After heat treatment, the volume/shape of the obtained monolithic

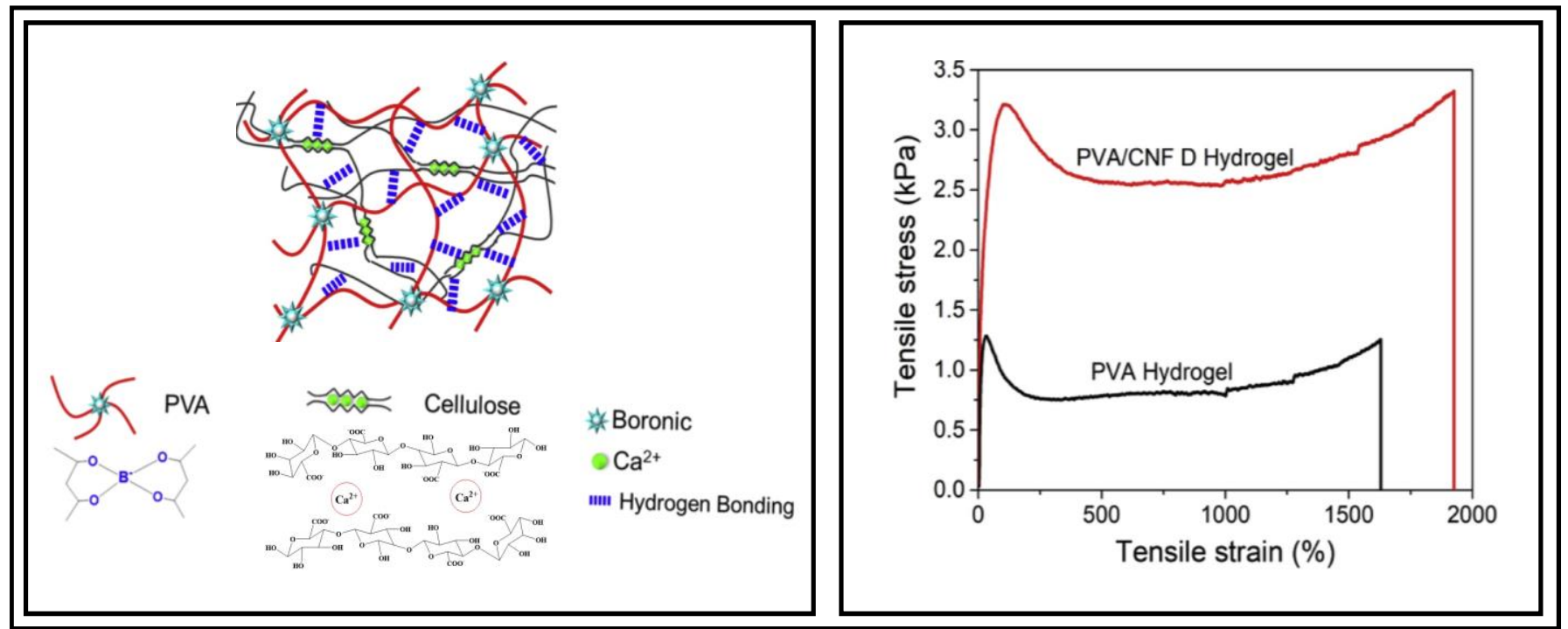

Fig. 9 (a) PVA/CNF D hydrogel network schematics. (b) The representative tensile stress-strain curves of PVA hydrogel and PVA/CNF D hydrogel. Reproduced with permission from [120]. Copyright@Elsevier. 


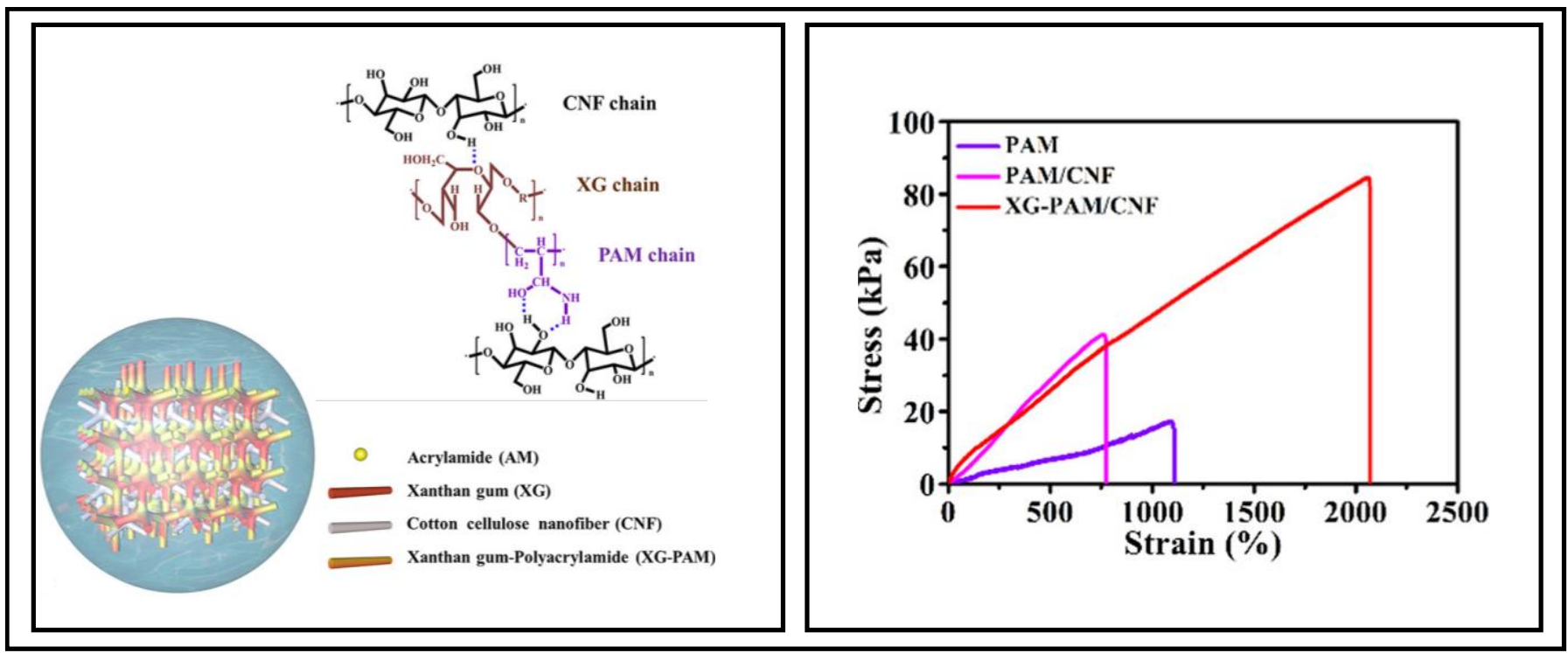

Fig. 10 (a) Schematic illustration of the XG-PAM/CNF hydrogel electrolyte film. Chemical structure of the XG-PAM/CNF hydrogel. (b) Stress-strain curves of the hydrogels. Reproduced with permission from [121]. Copyright@American Chemical Society.

Table 2. Comparison of different hydrogel properties.

\begin{tabular}{lllll}
\hline Gel name & $\begin{array}{l}\text { Conductivity } \\
(\mathrm{mS} / \mathrm{cm})\end{array}$ & $\begin{array}{l}\text { The fracture tensile } \\
\text { strain }\end{array}$ & Transmittance & Ref. \\
\hline $\begin{array}{l}\text { CNC@P(SBMA-co-AM) } \\
\begin{array}{l}\text { Zwitterionic Nanocomposite } \\
\text { Hydrogels }\end{array}\end{array}$ & 36.74 & $1127 \%$ & $>85 \%$ & {$[119]$} \\
$\begin{array}{l}\text { Polyvinyl alcohol/cellulose } \\
\text { nanofibril hydrogel }\end{array}$ & 30.00 & $1900 \%$ & $>90 \%$ & {$[120]$} \\
$\begin{array}{l}\text { XG-PAM / CNF } \\
\text { X }\end{array}$ & 28.80 & $2070 \%$ & $>80 \%$ & {$[121]$} \\
\hline
\end{tabular}

carbon material can be well maintained. The effects of RGO content and annealing conditions on EMI shielding and $\mathrm{P}$ mechanical properties were studied. In addition, even under large strains ( $80 \%$ reversible compressibility), hybrid aerogels have excellent mechanical elasticity and excellent cycle stability. In addition, the adjustable EMI shielding capability can be achieved through simple mechanical compression. ${ }^{[127]}$

Zhuo ${ }^{[128]}$ improved RGO aerogels further to have not only high elasticity but also a stable response to variable current. It can be proved that by designing a wave-shaped RGO layer and enhancing the interaction between the RGO layers, graphene oxide (RGO)-based layered carbon with unexpected comprehensive properties can be prepared. The addition of cellulose nanocrystals and low-molecular-weight carbon precursors enhances the interaction between the RGO layers, thereby forming an ultra-light, flexible and ultra-stable structure. The prepared carbon aerogel shows excellent compressibility (withstand $99 \%$ of ultimate strain) and elasticity $(100 \%$ high retention force after 10,000 cycles under $30 \%$ strain) and stable strain current response (at least 10,000 cycles). In particular, carbon aerogels are very sensitive to detecting small changes in strain $(0.012 \%)$ and pressure $(0.25$ $\mathrm{Pa}$ ), which is the lowest detection limit of compressible carbon materials reported in the literature. In addition, carbon aerogel has excellent bendability and can detect an ultra-low bending angle of $0.052^{\circ} .{ }^{[128]}$

Apparently, the cellulose gel materials have been improved in terms of mechanical properties after years of research and exploration, and now it can be used to monitor various human movements, including vocalization, swallowing process, finger movement and limb movement. However, cellulose gel still has a long way to go in terms of flexible sensing devices, such as the signal transmission between human-computer interaction devices and users. For instance, the mechanisms by which the gel work in cold winters need to be further studied. ${ }^{[129]}$

\subsection{Medical}

3.3.1 Cellulose gel for flexible sensing applications in medical treatment

The rapid development of flexible electronics makes them well suited for applications in medical care and preventive 
medicine. Recently, many high-performance cellulose-based flexible electronic devices have been developed, including wearables based on fabrics, electronics that fit on the skin (Fig. 11a), and fully implantable devices. ${ }^{[130-132]}$ Cellulose-based flexible electronic device have substrate, electrodes, sensors, flexible display, flexible energy collection and storage device that can monitor human activities in real time. A flexible electronic device made of a polymer composite material is flexible and elastic. It typically consists of a substrate, electrodes, sensors, a flexible display and a flexible energy collection and storage device that can monitor human activities in real time. ${ }^{[133-135]}$ By interacting with human skin or organs to quantify the physical signals produced by the body, wearable sensor systems collect critical data needed by artificial intelligence algorithms. ${ }^{[136,137]}$ Cellulose-based wearable sensor systems show an ability to collect physiological and environmental data, such as blood pressure and oxygen, respiratory rate, heart rate, temperature, movement and so on. For example, sensors absorb sweat during exercise, analyze its ion concentration, and combine it with signals like heartbeat, breathing, and temperature to represent a subject's health. ${ }^{[138]}$ Flexible strain sensors based on cellulose composites with functional properties can be made into various forms according to different gel properties. ${ }^{[139]}$ But since a single signal, such as heartbeat and breathing, cannot fully represent a person's health, the device needs to be able to detect a variety of human movements. ${ }^{[140]}$ For example, the $\mathrm{CNF}$ aerogel has a unique 3D network, which makes it highly flexible, compressible to a $90 \%$ reduction in volume, and has a correlation between resistance and compressive strain. Therefore, it can be compressed in the form of aerogel and is expected to be used in pressure sensing. ${ }^{[141]}$ In a wide range of pore delignification wood introduced in chemistry and ionic cross-linking polyacrylic acid (PAA) preparation of gel, the gel slices with RGO thin film electrode holder in capacitive pressure sensor, can improve stress coping ability and used to simulate the mechanical and sensing function of muscle tissue. While a wide detection stress range (about $1.6 \mathrm{MPa}$ ) to meet the stability of human activities monitoring (Fig. 11b) can simulate the mechanical and sensing functions of muscle tissue, the sensitivity is not good. ${ }^{[142]}$ The double-crosslinked hydrogels with microcrystalline and borate bonds have excellent biocompatibility and rapid resistance to strain exerted, and their sensitivity is obviously better than the former, which can detect the joint motion of human body and is suitable for human health management. Chlorinated naphthalene-abscisic acid was first prepared by periodate oxidation and reductive amination, and then mixed with Multiwalled carbon nanotubes (MWNTs) and polyvinyl alcohol (Fig. 11d). The tensile strength, elongation at break and elastic modulus of the hydrogel reached $227 \mathrm{KPa}, 395 \%$ and 9000 $\mathrm{KPa}$, respectively (Fig. 11c). Multi-walled carbon nanotubes and sodium hydroxide can cooperate to improve the electrical conductivity of hydrogels. The hydrogel also has excellent self-healing ability, with a healing rate of $97 \%{ }^{\left[{ }^{[143]}\right.}$ The hydrogels prepared by deposing negatively charged polyelectrolyte carboxymethyl cellulose directly into bacterial cellulose matrix can be used as colorimetric $\mathrm{pH}$ sensors with fast response and linear correlation in the $\mathrm{pH}$ range of 4.0 9.0 (Fig. 11e). For the detection of glucose in sweat, the colorimetric glucose sensor based on Bacterial Cellulose carboxymethyl Cellulose Sodium (BC/CMC) has a low detection limit (25 microns), wide linear detection range (0$0.5 \mathrm{~mm}$ ) and high accuracy. Therefore, it can be applied to skin health monitoring. The health of the human body is more subtle. ${ }^{[144]}$ The various properties, advantages and application comparisons of cellulose gels are summarized in (Table 3). In addition, the RGO-coated cell wall assembled with the crossfingered electrode results in a pressure sensor with a response time of about $150 \mathrm{~ms}$ and a recovery time of about $100 \mathrm{~ms}$, which can be used to detect small pressures. Examples include identifying complex arterial pulse signals, thus highlighting its potential applications in real-time healthcare and medical diagnostics. ${ }^{[145]}$

\subsubsection{Other medical applications of cellulosic gels}

3D printing technology plays a crucial role in creating functional tissues and organs. Although many biomaterials have been developed and applied, most of them are not compatible with existing bio-printing technologies. The bioprintability of hydrogels as the most common bioink, is better than other bioink types, and can be used as an ideal bioink material to fabricate scaffolds for carrying living cells. ${ }^{[146]}$ For example, hydrogels made from alginate, natural cellulose, can be cross-linked with ions in calcium carbonate or calcium sulfate solutions. It is also possible to change the

Table 3. Comparison of properties and applications of cellulose-based gel sensors.

\begin{tabular}{|c|c|c|c|c|c|}
\hline The raw material & $\begin{array}{l}\begin{array}{l}\text { Elongation at } \\
\text { break }\end{array} \\
\end{array}$ & Disadvantages & Advantages & Application & Origins \\
\hline PAA, rGO & $9.80 \%$ & Low sensitivity & $\begin{array}{l}\text { Wide detection range, } \\
\text { good compression } \\
\text { resilience }\end{array}$ & $\begin{array}{l}\text { Muscle tissue mechanics } \\
\text { and sensing }\end{array}$ & {$[142]$} \\
\hline $\begin{array}{l}\text { CNCs-ABA, } \\
\text { MWCNT, PVA }\end{array}$ & $395 \%$ & Low tensile strength & Self-healing ability & $\begin{array}{l}\text { Monitor the movement of } \\
\text { human joints }\end{array}$ & {$[143]$} \\
\hline $\mathrm{CMC}, \mathrm{BC}$ & 1 & $\begin{array}{l}\text { Slow response } \\
\text { (outside linear range) }\end{array}$ & $\begin{array}{l}\text { Low detection limit, } \\
\text { high precision }\end{array}$ & Skin Health Monitoring & {$[144]$} \\
\hline
\end{tabular}


concentration of hydrogel and crosslinking time without changing the cell morphology. Mixed hydrogels prepared by different concentrations and proportions of gelatin and alginate can show different properties as printing materials. ${ }^{[147]}$ The combination of alginate and other functional materials can improve the mechanical properties of bio-printed structures. Bacterial cellulose (Fig. 12a), with its three-dimensional network and high porosity, facilitates the exchange of nutrients, oxygen and waste between cells. Compared with alginate, it can be better used in biomedicine. Due to the presence of hydroxyl groups between molecules, bacterial cellulose hydrogels can form intramolecular and intermolecular hydrogen bonds, thus having certain self-healing ability. ${ }^{[148]} \mathrm{A}$ large number of studies have shown that bacterial cellulose is a promising biomaterial with large specific surface area, abundant surface hydroxyl groups, diverse and superior mechanical properties, cellular compatibility, biodegradability and renewability. BNC breaks new ground in the development of medical materials and drug delivery systems for cardiovascular and visceral surgery. ${ }^{[149]}$ The composite materials based on it are expected to be used more widely in the future (Fig. 12b). ${ }^{[150]}$ On account of biodegradable and biocompatible nature, cellulose gels have several other applications in medical field. For example, bacterial cellulose hydrogel (Fig. 12c) has a high water holding capacity and the potential to hold water for a long period of time with slow release, and can therefore be used for the treatment of refractory wounds, skin ulcers, bedsores, burns, and wounds requiring frequent changes of dressing. ${ }^{[151]}$ Maneron et al. prepared bacterial cellulose-silver nanocomposites by impregnating bacterial cellulose sheets in silver nitrate solution, which showed strong antibacterial activity against both Gram-positive and Gram-negative bacteria. ${ }^{[152]}$ Maria et al. conducted a similar study, resulting in a bacterial cellulosesilver nanocomposite with a strong bactericidal effect against E. coli. Bacterial cellulose-silver composites have been found to be effective against a variety of bacteria and fungi, thus reducing the chance of wound infection and allowing wounds to heal quickly and safely. ${ }^{[153]}$

\section{Summary and Prospect}

These two documents have provided inspiration for the framework of the writing of this article, ${ }^{[154,155]}$ after sorting out the documents we consulted, we can also summarize some conclusions about the development of cellulose gel. As a green and environmentally friendly material, cellulose has numerous merits, including characteristics of renewable and degradable, low cost, good biocompatibility, and good flexibility, these advantages make it an attractive substrate and component for flexible electronics. Despite many achievements in developing cellulosic materials for flexible electronic devices, there are still some issues that should be addressed. As an application

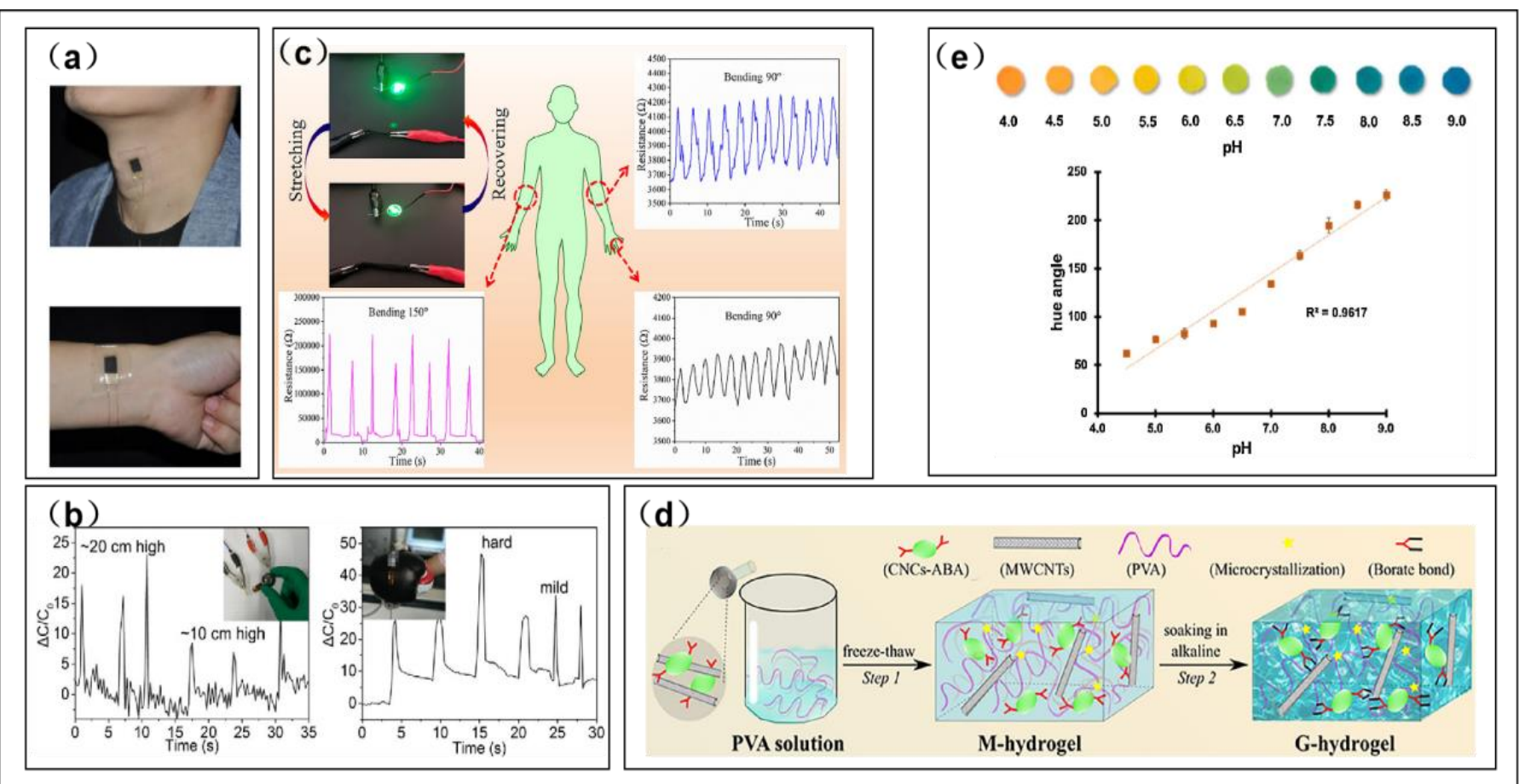

Fig.11 (a)Various flexible, skin-mountable, and wearable strain sensors made of functional nanomaterials-polymer composites. Reproduced with permission from [145]. Copyright@American Chemical Society. (b) The real-time capacitance rate signals and images of monitoring of dropping of small beads and boxing. Reproduced with permission from [142]. Copyright@American Chemical Society. (c) Strain sensor as the G type resistance change of water gel to monitor elbow and elbow under different bending Angle of straightening and bending condition. Reproduced with permission from [143]. Copyright@Elsevier. (d) Double crosslinking network diagram. Reproduced with permission from [143]. Copyright@Elsevier. (e) The $\mathrm{pH}$ of the preparation of hydrogels in the linear range of the $\mathrm{BC} / \mathrm{CMC}$ type standard color image and calibration chart pH sensor. Reproduced with permission from [144]. Copyright@Elsevier. 


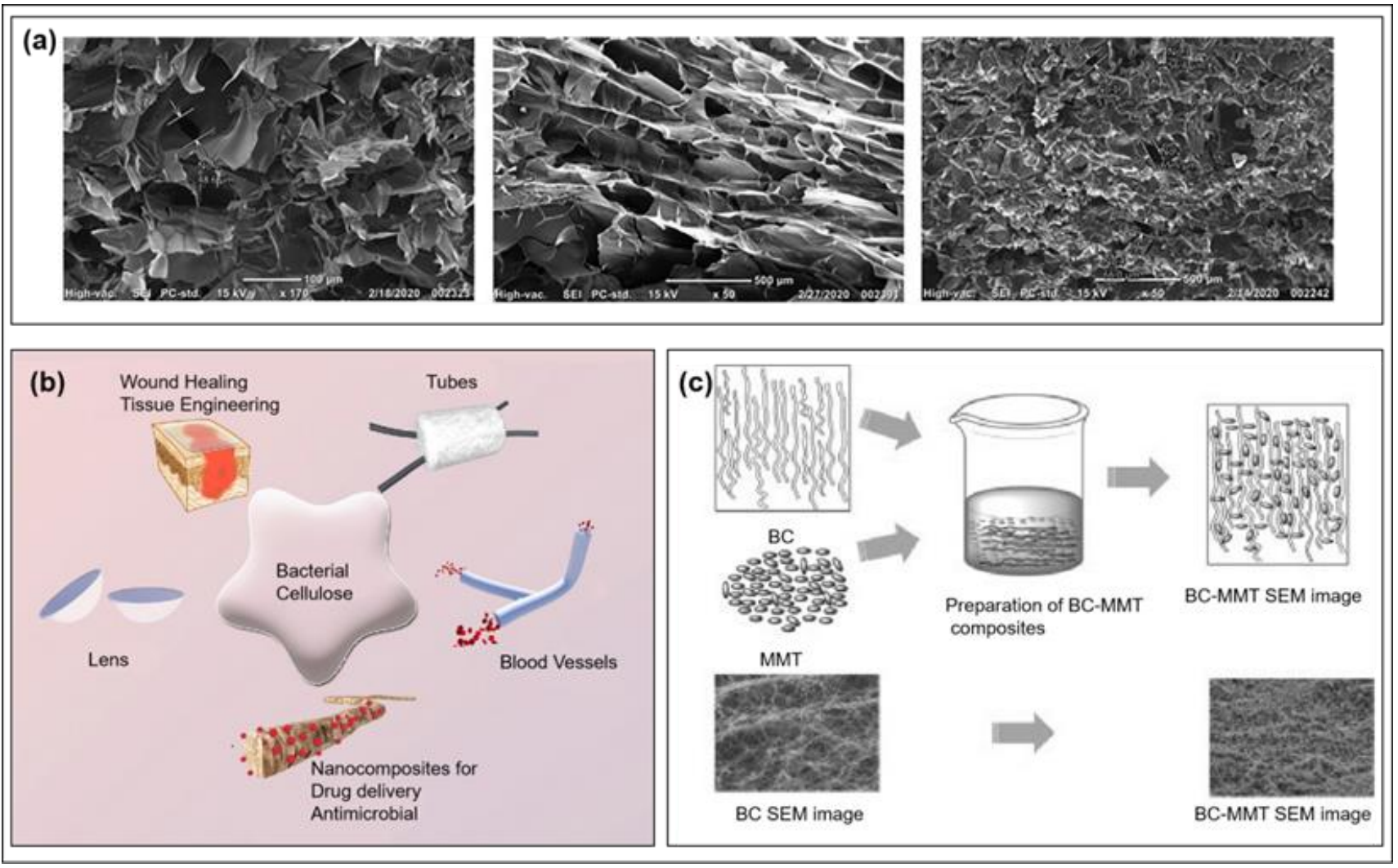

Fig. 12 Bioprintedhydrogels: (a) The SEM micrographs of gelatin-alginate brine gels with different mixing ratios showed that the porosity of the three gels. Reproduced with permission from [147]. Copyright@Elsevier. (b) Application of bacterial cellulose in medical treatment. Reproduced with permission from [150]. Copyright@Elsevier. (c) Scanning electron microscope image of bacterial nanocellulose. Reproduced with permission from [151]. Copyright@Elsevier.

direction of cellulose gel flexible sensor, electronic skin is the basis of other applications. Skin-like wearable and implantable bioelectronic devices with excellent flexibility, wearability and high sensitivity show great hope for personalized disease treatment, health maintenance, and tissue and organ repair. It can be used to monitor various human movements, including vocalization, swallowing process, finger movement and limb movement, and provide real-time feedback, so how to ensure that the electrons are evenly spread in flexible materials, and can work in different environments like human skin. ${ }^{[68,107-111]}$ Responsiveness is our key development direction in the future. However, the gel still cannot work normally in the cold winter and other non-mild environments. ${ }^{[129]}$ Therefore, to realize the idea of electronic skin, we need to conduct basic research in many aspects in terms of materials, technology, and performance. Cellulosebased gel materials for flexible sensing devices still face some big challenges, but they also represent a whole new approach to seamlessly merge biology and wearable electronics. In the future application market, cellulose flexible sensing materials are likely to achieve remarkable progress by virtue of their own advantages.

\section{Acknowledgement}

This work was supported by the Innovation and Entrepreneurship Training Project for Northeast Forestry
University College Students (DC2020113).

\section{References}

[1] B. Tan, C. Yern, P. Sin, A. Luqman and G. Seng, Polymers, 2015, 7, 2205-2222, doi: 10.3390/polym7111509.

[2]. S. C. B. Mannsfeld, B. C. K. Tee, R. M. Stoltenberg, C. Chen, S. Barman, B. V. O. Muir, A. N. Sokolov, C. Reese and Z. N. Bao, Nat. Mater., 2010, 9, 859-864, doi: 10.1038/nmat2834.

[3] U. G. T. M. Sampath, Y. C. Ching, C. H. Chuah, J. J. Sabariah and P.-C. Lin, Materials, 2016, 9, 991, doi: 10.3390/ma9120991. [4] J. Chen, J. Zheng, Q. Gao, J. Zhang, J. Zhang, O. M. Omisore, L. Wang and H. Li, Appl. Sci-Basel, 2018, 8, 345, doi: 10.3390/app8030345.

[5] K. C. Pradel, W. Wu, Y. Ding and Z. L. Wang, Nano Lett., 2014, 14, 6897-6905, doi: 10.1021/n15029182.

[6] C.-H. Zhang, Y. Yang, Y.-F. Wang, C.-J. Zhou, Y. Shu, H. Tian and T.-L. Ren, Chinese Phys. Lett., 2013, 30, 086201, doi: 10.1088/0256-307X/30/8/086201.

[7] W. P. Shih, L. C. Tsao, C. W. Lee, M. Y. Cheng, C. Chang, Y. J. Yang and K. C. Fan, Sensors, 2010, 10, 3597-3610, doi: $10.3390 / \mathrm{s} 100403597$.

[8] Kenry, J. C. Yeo and C. T. Lim, J. Laser. Micro. Nanoen., 2016, 2, 19, doi: 10.1038/micronano.2016.43.

[9] J.-H. Kong, N.-S. Jang, S.-H. Kim and J.-M. Kim, Carbon, 2014, 77, 199-207, doi: 10.1039/c3nr04629j.

[10] Y. Zhou, C. Chen, S. Zhu, C. Sui, C. Wang, Y. Kuang, U. Ray, D. Liu, A. Brozena, U. H. Leiste, N. Quispe, H. Guo, A. Vellore, H. A. Bruck, A. Martini, B. Foster, J. Lou, T. Li and L. Hu, Mater. Today, 2019, 30, 17-25, doi: 10.1016/j.mattod.2019.03.016. 
[11] H.-W. Liang, Q.-F. Guan, Z. Zhu, L.-T. Song, H.-B. Yao, X. Lei and S.-H. Yu, Npg Asia Mater., 2012, 4, doi: 10.1038/am.2012.34.

[12] E. R. P. Keijsers, G. Y1lmaz and J. E. G. van Dam, Carbohydr. Polym., 2013, 93, 9-21, doi: 10.1016/j.carbpol.2012.08.110.

[13] D. Klemm, F. Kramer, S. Moritz, T. Lindström, M. Ankerfors, D. Gray and A. Dorris, Angew. Chem. Int. Edit., 2011, 50, 54385466, doi: 10.1002/ange.201001273.

[14] D. W. Zhao, Y. Zhu, W. K. Cheng, W. S. Chen, Y. Q. Wu and H. P. Yu, Adv. Mater. 2020, 2000619, doi: 10.1002/adma.202000619.18.

[15] S. Ummartyotin and H. Manuspiya, Renew. Sust. Energ. Rev., 2015, 41, 402-412, doi: 10.1016/j.rser.2014.08.050.

[16] H. L. Zhu, W. Luo, P. N. Ciesielski, Z. Q. Fang, J. Y. Zhu, G. Henriksson, M. E. Himmel and L. B. Hu, Chem. Rev., 2016, 116, 9305-9374, doi: 10.1021/acs.chemrev.6b00225.

[17] S. Kamel, N. Ali, K. Jahangir, S. M. Shah and A. A. El-Gendy, Express Polym. Lett., 2008, 2, 758-778, doi: 10.3144/expresspolymlett.2008.90.

[18] D. Klemm, B. Heublein, H. P. Fink and A. Bohn, Angew. Chem. Int. Edit., 2004, 44, 3358-3393, doi: 10.1002/ange.200460587.

[19] R. J. Moon, A. Martini, J. Nairn, J. Simonsen and J. Youngblood, Chem. Soc. Rev., 2011, 40, 3941-3994, doi: 10.1002/chin.201142280.

[20] Gibson and J. L., J. R. Soc Interface, 2012, 9, 2749-2766, doi: 10.1098/rsif.2012.0341.

[21] A. J. Bidhendi and A. Geitmann, J. Exp. Bot., 2015, 67, 449461, doi: $10.1093 / \mathrm{j} x b /$ erv535.

[22] S. Ling, W. Chen, Y. Fan, K. Zheng, K. Jin, H. Yu, M. J. Buehler and D. L. Kaplan, Prog. Polym. Sci., 2018, 85, 1-56, doi: 10.1016/j.progpolymsci.2018.06.004.

[23] N. Masruchin, B.-D. Park, V. Causin and I. C. Um, Cellulose, 2015, 22, 1993-2010, doi: 10.5658/WOOD.2015.43.5.613.

[24] S. J. Eichhorn, A. Dufresne, M. Aranguren, N. E. Marcovich, J. R. Capadona, S. J. Rowan, C. Weder, W. Thielemans, M. Roman, S. Renneckar, W. Gindl, S. Veigel, J. Keckes, H. Yano, K. Abe, M. Nogi, A. N. Nakagaito, A. Mangalam, J. Simonsen, A. S. Benight, A. Bismarck, L. A. Berglund and T. Peijs, J. Mater. Sci., 2010, 45, 1-33, doi: 10.1007/s10853-009-3874-0.

[25] C. Salas, T. Nypelo, C. Rodriguez-Abreu, C. Carrillo and O. J. Rojas, Curr. Opin. Colloid In., 2014, 19, 383-396, doi: 10.1016/j.cocis.2014.10.003.

[26] H. S. Du, W. M. Liu, M. L. Zhang, C. L. Si, X. Y. Zhang and B. Li, Carbohydr. Polym., 2019, 209, 130-144, doi: 10.1016/j.carbpol.2019.01.020.

[27] P. Zugenmaier, Carbohydr. Polym., 2021, 253, 117218, doi: 10.1016/j.carbpol.2020.117417.

[28] A. F. Turbak, F. W. Snyder and K. R. Sandberg, J.Appl. Polym. Sci. Appl. Polym. Symp, 1983.

[29] D. Y. Kim, Y. Nishiyama and S. Kuga, Cellulose, 2002, 9, 361-367, doi: 10.1023/A:1021140726936.

[30] S. Ifuku, M. Nogi, K. Abe, K. Handa, F. Nakatsubo and H. Yano, Biomacromolecules, 2007, 8, 1973-1978, doi: 10.1021/bm070113b.

[31] C. Gousse, H. Chanzy, M. L. Cerrada and E. Fleury, Polymer, 2004, 45, 1569-1575, doi: 10.1016/j.polymer.2003.12.028.

[32] M. Andresen, L. S. Johansson, B. S. Tanem and P. Stenius, Cellulose, 2006, 13, 665-677, doi: 10.1007/s10570-006-9072-1.

[33] H. P. S. Abdul Khalil, A. H. Bhat and A. F. Ireana Yusra, Carbohydr. Polym., 2012, 87, 963-979, doi: 10.1016/j.carbpol.2011.08.078.

[34] O. Wichterle and D. LÍM, Nature, 1960, 185, 117-118, doi: 10.1038/185117a0.

[35] K. Nagahama, T. Ouchi and Y. Ohya, Adv. Funct. Mater., 2008, 18, 1220-1231, doi: 10.1002/adfm.200700587.

[36] P. J. Martens, S. J. Bryant and K. S. Anseth, Biomacromolecules, 2003, 4, 283-292, doi: 10.1021/bm025666v. [37] A. K. Bajpai, S. K. Shukla, S. Bhanu and S. Kankane, Prog. Polym. Sci., 2008, 33, 1088-1118, doi: 10.1016/j.progpolymsci.2008.07.005.

[38] Y. J. Lee and P. V. Braun, Adv. Mater, 2010, 15, doi: 10.1002/adma.200304588.

[39] J. Sorber, G. Steiner, V. Schulz, M. Guenther, G. Gerlach, R. Salzer and K. F. Arndt, Anal. Chem., 2008, 80, 2957-2962, doi: 10.1021/ac702598n.

[40] C. Chang and L. Zhang, Carbohydr. Polym., 2011, 84, 40-53, doi: 10.1016/j.carbpol.2010.12.023.

[41] A. K. A. Silva, C. Richard, M. Bessodes, D. Scherman and O. W. Merten, Biomacromolecules, 2009, 10, 9-18, doi: 10.1021/bm801103c.

[42] A. E. Way, L. Hsu, K. Shanmuganathan, C. Weder and S. J. Rowan, ACS Macro. Lett., 2012, 1, 1001-1006, doi: $10.1021 / \mathrm{mz} 3003006$.

[43] M. Chau, S. E. Sriskandha, D. Pichugin, H. Therien-Aubin, D. Nykypanchuk, G. Chauve, M. Methot, J. Bouchard, O. Gang and E. Kumacheva, Biomacromolecules, 2015, 16, 2455-2462, doi: 10.1021/acs.biomac.5b00701.

[44] K. J. De France, T. Hoare and E. D. Cranston, Chem. Mat., 2017, 29, 4609-4631, doi: 10.1021/acs.chemmater.7b00531.

[45] W. Q. Kong, C. W. Wang, C. Jia, Y. D. Kuang, G. Pastel, C. J. Chen, G. G. Chen, S. M. He, H. Huang, J. H. Zhang, S. Wang and L. B. Hu, Adv. Mater, 2018, 30, 7, doi: 10.1002/adma.201801934.

[46] S. Sultan and A. P. Mathew, Nanoscale, 2018, 10, 4421-4431, doi: $10.1039 / \mathrm{c} 7 \mathrm{nr} 08966 \mathrm{j}$.

[47] C. Xu, B. Z. Molino, X. Wang, F. Cheng, W. Xu, P. Molino, M. Bacher, D. Su, T. Rosenau, S. Willfoer and G. Wallace, J. Mater. Chem. B, 2018, 6, 7066-707, doi: 10.1039/C8TB01757C. [48] S. Schwarz, H. M. Avila, N. Rotter and P. Gatenholm, Tissue Eng. Pt. A, 2015, 21, S373-S373, doi: 10.1089/ten.TEA.2013.0561.

[49] S. S. Kistler, Nature, 1932, 5, 600-603, doi: $10.5254 / 1.3539386$

[50] N. Leventis, C. Sotiriou-Leventis, G. Zhang and A. Rawashdeh, Nano Lett., 2002, 2, 957-960, doi: 10.1021/n1025690e.

[51] A. Katti, N. Shimpi, S. Roy, H. Lu and N. Leventis, Chem. Mat., 2006, 18, doi: 10.1021/cm0513841

[52] T. Miyamoto, S. Takahashi, H. Ito, H. Inagaki and Y. Noishiki, J. Biomed Mater. Res., 1989, 23, 125-133, doi: 10.1002/jbm.820230110.

[53] S. R. Ma, Q. Y. Mi, J. Yu, J. S. He and J. Zhang, Prog. Chem., 2014, 26, 796-809, doi: 10.7536/PC131032.

[54] Z. Wang, S. Liu, Y. Matsumoto and S. Kuga, Cellulose, 2012, 19, 393-399, doi: 10.1007/s10570-012-9651-2.

[55] L. Y. Long, Y. X. Weng and Y. Z. Wang, Polymers, 2018, 10, 708, doi: 10.3390/polym10070708.

[56] S. Lee, M.-J. Jeong and K.-Y. Kang, J. Korean Phys. Soc., 2015, 67, 738-741, doi: 10.3938/jkps.67.738.

[57] M.-J. Jeong, S. Lee, K.-Y. Kang and A. Potthast, J. Korean Phys. Soc., 2015, 67, 742-745, doi: 10.3938/jkps.67.742. 
[58] J. Fu, S. Wang, C. He, Z. Lu, J. Huang and Z. Chen, Carbohydr. Polym., 2016, 147, 89-96, doi: 10.1016/j.carbpol.2016.03.048.

[59] H. Sai, L. Xing, J. Xiang, L. Cui, J. Jiao, C. Zhao, Z. Li, F. $\mathrm{Li}$ and T. Zhang, RSC Adv, 2014, 4, 30453-30461, doi: $10.1039 / \mathrm{c} 4 \mathrm{ra} 02752 \mathrm{c}$

[60] Y. Fang, S. Chen, X. Luo, C. Wang, R. Yang, Q. Zhang, C. Huang and T. Shao, RSC Adv., 2016, 6, 54054-54059, doi: 10.1039/C6RA06067F.

[61] J. Cai, S. Kimura, M. Wada, S. Kuga and L. Zhang, Chem. Sus. Chem., 2010, 1, 149-154, doi: 10.1002/cssc.200700039.

[62] X. Zhang, Y. Yu, Z. Jiang and H. Wang, J. Wood Sci., 2015, 61, 595-601, doi: 10.1007/s10086-015-1514-7.

[63] H. Hosseini, M. Kokabi and S. M. Mousavi, Carbohydr. Polym., 2018, 201, 228-235, doi: 10.1016/j.carbpol.2018.08.054. [64] H. Jin, Y. Nishiyama, M. Wada and S. Kuga, Colloid. Surface A, 2004, 240, 63-67, doi: 10.1016/j.colsurfa.2004.03.007.

[65] R. Lopez-Blanco, M. A. Velasco, A. Mendez-Guerrero, J. Pablo Romero, M. Dolores del Castillo, J. Ignacio Serrano, E. Rocon and J. Benito-Leon, J. Neurol. Sci., 2019, 401, 37-42, doi: 10.1016/j.jns.2019.04.011.

[66] M. El Gharbi, R. Fernández-García, S. Ahyoud and I. Gil, Materials, 2020, 13, doi: 10.3390/ma13173781

[67] J. Huang, D. Li, M. Zhao, P. Lv, L. Lucia and Q. Wei, Cellulose, 2019, 26, 3401-3413, doi: 10.1007/s10570-01902313-3.

[68] Z. Chen, T. Yan and Z. Pan, Cellulose, 2021, 28, 615-645, doi: 10.1007/s10570-020-03543-6.

[69] H. Kargarzadeh, M. Mariano, D. Gopakumar, I. Ahmad, S. Thomas, A. Dufresne, J. Huang and N. Lin, Cellulose, 2018, 25, 2151-2189, doi: 10.1007/s10570-018-1723-5.

[70] M. Amjadi, K. Kyung, I. Park and M. Sitti, Adv. Funct. Mater., 2016, 26, doi: 10.1002/adfm. 201504755.

[71] W. C. A. B, H. Y. A. B, Y. L. A. B, P. C. B, M. Z. B and Y. H. B, Carbohydr. Polym., 2011, 83, 1804-1811, doi: 10.1016/j.carbpol.2010.10.040.

[72] Z. Zhou, C. Qian and W. Yuan, Compos. Sci. Technol., 2021, 203, 108608, doi: 10.1016/j.compscitech.2020.108608.

73. H. Zhang, X. Sun, M.A. Hubbe, L. Pal, ACS Applied Electronic Mater, 2019, 1, 1179-1188, doi: 10.1021/acsaelm.9b00182.

[74] C. Shao, L. Meng, C. Cui and J. Yang, J. Mater. Chem. C, 2019, 7, doi: 10.1039/c9tc05467g.

[75] J. C. Yang, J. Mun, S. Y. Kwon, S. Park and S. Park, $A d v$. Mater., 2019, 31, doi: 10.1002/adma.201904765.

[76] Petersen and Gatenholm, Appl. Microbiol. Biot., 2011, 91, 1277-1286, doi: 10.1007/s00253-011-3432-y.

[77] Binghua, Zou, Yuanyuan, Chen, Yihan, Liu, Ruijie, Xie, Qinjie and Tao, $A d v$. Sci., 2018, 6, 1801283-1801283, doi: 10.1002/advs.201801283.

[78] D. W. Marhefka, N. Venkataraman and S. Barua, SID, 2009, 810-813, doi: 10.1889/1.3069793.

[79] T. Sekitani and T. Someya, MRS Bull., 2012, 37, 236-245, doi: 10.1557/mrs.2012.42.

[80] H. Xu, Y. Xie, E. Zhu, Y. Liu, Z. Shi, C. Xiong, Q. Yang, $J$ Mater Chem A, 2020, 8, 6311-6318, doi: 10.1039/D0TA00158A. [81] A. B. Wan, H. Sanghyun, S. Ji, B. Franklin and P. Jang-Ung, Nat. Commun., 2018, 9, 2458-, doi: 10.1038/s41467-018-049061.

[82] Y. Kim, A. Chortos, W. Xu, Y. Liu, J.Y. Oh, D. Son, J. Kang, A.M. Foudeh, C. Zhu, Y. Lee, Science, 2018, 360, 998-1003, doi: 10.1126/science.aao0098.

[83] D. Zhao, Y. Zhu, W. Cheng, G. Xu and L. Hu, Matter, 2019, 2, doi: 10.1016/j.matt.2019.10.020.

[84] Tran, Quang, Trung, Subramaniyan, Ramasundaram, Byeong-Ung, Hwang, Nae-Eung and Lee, Adv. Mater., 2015, 28, 502-509, doi: 10.1002/adma.201504441.

[85] M. A. Haque, G. Kamita, T. Kurokawa, K. Tsujii and P. G. Jian, Adv. Mater, 2010, 22, 5110-5114, doi: 10.1002/adma.201002509.

[86] M. Liao, P. Wan, J. Wen, M. Gong, X. Wu, Y. Wang, R. Shi and L. Zhang, Adv. Funct. Mater, 2017, 27, 1703852, doi: 10.1002/adfm.201703852.

[87] S. F. Chin, A. B. Romainor and S. C. Pang, Materials Letters, 2014, 115, 241-243, doi: 10.1016/j.matlet.2013.10.061.

[88] Y. Tang, H. Wang, D. Hou, H. Tan, M. Yang, J. Appl. Polym. Sci., 2020, 137, doi: 10.1002/app.49127.

[89] D. P. Mohite, S. Mahadikkhanolkar, H. Luo, H. Lu, C. Sotiriouleventis, Soft. Matter., 2013, 9, 1531-1539, doi: $10.1039 / \mathrm{c} 2 \mathrm{sm} 27606 \mathrm{~b}$.

[90] C. Jie, S. Kimura, M. Wada, S. Kuga and L. Zhang, Chemsuschem, 2010, 1, 149-154, doi: 10.1002/cssc.200700039.

[91] Shao, CY, Wang, Meng, Chang, HL and Xu, Chem. Mater., 2018, 30, 3110-3121, doi: 10.1021/acs.chemmater.8b01172.

[92] M. I. Oh, M. Gupta, I. O. Chang and D. F. Weaver, Phys. Chem. Chem. Phys., 2019, 21, doi: 10.1021/acs.jpcc.9b11442.

[93] M. A. Klingshirn, S. K. Spear, J. D. Holbrey and R. D. Rogers, J. Mater. Chem., 2005, 15, 5174-5180, doi: 10.1039/b508927a.

[94] M. Shahinpoor, Smart. Mater. Struct., 1994, 3, 367-372, doi: 10.1088/0964-1726/3/3/012.

[95] G. Su, S. Yin, Y. Guo, F. Zhao and G. Yu, Mater. Horiz., 2021, doi: $10.1039 / \mathrm{d} 1 \mathrm{mh} 00085 \mathrm{c}$.

[96] S. Demirci and N. Sahiner, J. Mol. Liq., 2014, 194, 85-92, doi: 10.1016/j.molliq.2014.01.015.

[97] P. Wang, D. Pei, Z. Wang, M. Li and C. Li, J. Mol. Liq., 2020, 398, 125540, doi: 10.1016/j.cej.2020.125540.

[98] Y. J. Liu, W. T. Cao, M. G. Ma and P. Wan, ACS Appl. Mater. Interfaces, 2017, 9, 25559-25570, doi: 10.1021/acsami.7b07639. [99] Xin, Jing, Heng, Li, Hao-Yang, Mi, Yue-Jun, Liu and PeiYong, Sensor. Actuat. B-Chem., 2019, 295, 159-167, doi: 10.1016/j.snb.2019.05.082.

[100] S. Dai, S. Wang, H. Yan, J. Xu and N. Yuan, Mater. Res. Express, 2019, 6, 0850b9, doi: 10.1088/2053-1591/ab2320.

[101] B. Guo, X. Ji, X. Chen, G. Li and J. Bai, Virtual Phys. Prototy, 2020, 15, 520-531, doi: 10.1080/17452759.2020.1823570.

[102] Y. Zhong, F. Seidi, C. Li, Z. Wan, H. Xiao, Biomacromolecules, 2021, 22, 1654-1663, doi: 10.1021/acs.biomac. $1 \mathrm{c} 00086$.

[103] H. A. A, R. H. A and C. C. B, Powder Technol., 2012, 217, 16-20, doi: 10.1016/j.powtec.2011.11.027.

[104] Marie, Krogsgaard, Vicki, Nue, Prof., Henrik and Birkedal, Phys. Chem. Glasses-B, 2016, 22, 844-857, doi: 10.1002/chem.201503380.

[105] Y. Zhou, C. Wan, Y. Yang, H. Yang, S. Wang, Z. Dai, K. Ji, H. Jiang, X. Chen and Y. Long, Adv. Funct. Mater, 2019, 29,1806220, doi: 10.1002/adfm.201806220.

[106] S. Pan, F. Zhang, P. Cai, M. Wang and X. Chen, Adv. Funct. Mater., 2020, 30, 1909540, doi: 10.1002/adfm. 201909540.

[107] L. Han, S. Cui, H. Y. Yu, M. Song, H. Zhang, N. Grishkewich, C. Huang, D. Kim and K. M. C. Tam, ACS Appl. 
Mater. Interfaces, 2019, 11, 44642-44651, doi: 10.1021/acsami.9b17030.

[108] C. Cui, Q. Fu, L. Meng, S. Hao, R. Dai and J. Yang, ACS Appl. Bio. Mater., 2020, 4, 85-121, doi: 10.1021/acsami.9b1581. [109] Y. Wang, L. Chen, H. Cheng, B. Wang, X. Feng, Z. Mao and X. Sui, Chem. Eng. J., 2020, 402, 126222, doi: 10.1016/j.cej.2020.126222.

[110] H. Zhuo, Y. Hu, Z. Chen, X. Peng, H. Lai, L. Liu, Q. Liu, C. Liu and L. Zhong, ACS Sustain. Chem. Eng., 2020, 8, $11921-$ 11929, doi: 10.1021/acssuschemeng.9b07833.

[111] C. Cui, C. Shao, L. Meng and J. Yang, ACS Appl. Mater. Interfaces, 2019, 11, 39228-39237, doi: 10.1021/acsami.9b15817. [112] Z. Peng, Y. Zou, S. Xu, W. Zhong and W. Yang, ACS Appl. Mater. Interfaces, 2018, 10, 22190-22200, doi: 10.1021/acsami.8b05171.

[113] T. Zhang, T. Zuo, D. Hu and C. Chang, ACS Appl. Mater. Interfaces, 2017, 9, 24230-24237, doi: 10.1021/acsami.7b06219. [114] M. Wang, Y. Chen, Y. Qin, T. Wang, J. Yang and F. Xu, ACS Sustain. Chem. Eng., 2019, 7, 12726-12733, doi: 10.1021/acssuschemeng.9b00814.

[115] M. Li, L. Zong, W. Yang, X. Li, J. You, X. Wu, Z. Li and C. Li, Adv. Funct. Mater, 2019, 29, doi: 10.1002/adfm.201901798. [116] Z. Chen, J. Liu, Y. Chen, X. Zheng, H. Liu and H. Li, ACS Appl. Mater. Interfaces, 2021, 13, 1353-1366, doi: 10.1021/acsami.0c16719.

[117] Z. Peng and W. Zhong, ACS Sustain. Chem. Eng., 2020, 8, 7879-7891, doi: 10.1021/acssuschemeng.0c01118.

[118] J. Leppiniemi, P. Lahtinen, A. Paajanen, R. Mahlberg, S. Metsa-Kortelainen, T. Pinomaa, H. Pajari, I. Vikholm-Lundin, P. Pursula and V. P. Hytonen, ACS Appl. Mater. Interfaces, 2017, 9, 21959-21970, doi: 10.1021/acsami.7b02756.

[119] B. Yang and W. Yuan, ACS Appl. Mater. Interfaces, 2019, 11, 40620-40628, doi: 10.1021/acsami.9b14040.

[120] X. Jing, H. Li, H.-Y. Mi, Y.-J. Liu, P.-Y. Feng, Y.-M. Tan and L.-S. Turng, Sensor. Actuat. B-Chem, 2019, 295, 159-167, doi: 10.1016/j.snb.2019.05.082.

[121] B. Wang, J. Li, C. Hou, Q. Zhang, Y. Li and H. Wang, ACS Appl. Mater. Interfaces, 2020, 12, 46005-46014, doi: 10.1021/acsami.0c12313.

[122] Z. Chen, H. Zhuo, Y. Hu, H. Lai, L. Liu, L. Zhong and X. Peng, Adv. Funct. Mater., 2020, 30, 1910292, doi: 10.1002/adfm.201910292.

[123] S. Long, Y. Feng, F. He, S. He, H. Hong, X. Yang, L. Zheng, J. Liu, L. Gan and M. Long, Carbon, 2020, 158, 137-145, doi: 10.1016/j.carbon.2019.11.065.

[124] D. C. Wang, H. Y. Yu, D. Qi, M. Ramasamy, J. Yao, F. Tang, K. M. C. Tam and Q. Ni, ACS Appl. Mater. Interfaces, 2019, 11, 24435-24446, doi: 10.1021/acsami.9b06527.

[125] Y. Hu, H. Zhuo, Z. Chen, K. Wu, Q. Luo, Q. Liu, S. Jing, C. Liu, L. Zhong, R. Sun and X. Peng, ACS Appl. Mater. Interfaces, 2018, 10, 40641-40650, doi: 10.1021/acsami.8b15439. [126] H. Hosseini, M. Kokabi and S. M. Mousavi, Carbohydr. Polym., 2018, 201, 228-235, doi: 10.1016/j.carbpol.2018.08.054. [127] Y.-J. Wan, P.-L. Zhu, S.-H. Yu, R. Sun, C.-P. Wong and W.H. Liao, Carbon, 2017, 115, 629-639, doi: 10.1016/j.carbon.2017.01.054.

[128] H. Zhuo, Y. Hu, X. Tong, Z. Chen, L. Zhong, H. Lai, L. Liu, S. Jing, Q. Liu, C. Liu, X. Peng and R. Sun, Adv. Mater., 2018, 30, e1706705, doi: 10.1002/adma.201706705.

[129] N. Sun, F. Lu, Y. Yu, L. Su, X. Gao and L. Zheng, ACS Appl. Mater. Interfaces, 2020, 12, 11778-11788, doi: 10.1021/acsami.0c00325.

[130] J. Lee, B. Llerena Zambrano, J. Woo, K. Yoon and T. Lee, Adv. Mater., 2020, 32, 1902532, doi: 10.1002/adma.201902532.

[131] K. Xu, Y. Lu and K. Takei, Adv. Mater. Technol-Us, 2019, 4, 1800628, doi:10.1002/admt.201800628.

[132] C. Choi, M. K. Choi, T. Hyeon and D.-H. Kim, ChemNanoMat, 2016, 2, 1006-1017, doi:10.1002/cnma.201600191.

[133] M. Amjadi, K.-U. Kyung, I. Park and M. Sitti, Adv Funct. Mater., 2016, 26, 1678-1698, doi: 10.1002/adfm.201504755.

[134] T. Yan, Z. Wang and Z.-J. Pan, Curr. Opin. Solid. St. M., 2018, 22, 213-228, doi: 10.1016/j.cossms.2018.11.001.

[135] W. Liu, M.-S. Song, B. Kong and Y. Cui, Adv. Mater., 2017, 29, 1603436, doi: 10.1002/adma.201603436.

[136] T. Q. Trung and N.-E. Lee, Adv Mater., 2016, 28, 43384372, doi: 10.1002/adma.201504244.

[137. B. C. K. Tee and J. Ouyang, Adv. Mater., 2018, 30, 1802560 , doi: 10.1002/adma.201802560.

[138] W. A. D. M. Jayathilaka, K. Qi, Y. Qin, A. Chinnappan, W. Serrano-García, C. Baskar, H. Wang, J. He, S. Cui, S. W. Thomas and S. Ramakrishna, Adv. Mater., 2019, 31, 1805921, doi: 10.1002/adma.201805921.

[139] Z. Chen, T. Yan and Z. Pan, Cellulose, 2021, 28, 615-645, doi: 10.1007/s10570-020-03543-6.

[140] H. Xu, Y. F. Lu, J. X. Xiang, M. K. Zhang, Y. J. Zhao, Z. Y. Xie and Z. Z. Gu, Nanoscale, 2018, 10, 2090-2098, doi: $10.1039 / \mathrm{c} 7 \mathrm{nr} 07225 \mathrm{~b}$.

[141] Z.-Y. Wu, C. Li, H.-W. Liang, J.-F. Chen and S.-H. Yu, Angew. Chem. Int. Edit., 2013, 52, 2925-2929, doi: 10.1002/ange.201301125.

[142] K. Nie, Z. Wang, R. Tang, L. Zheng, C. Li, X. Shen and Q. Sun, ACS Appl. Mater. Interfaces, 2020, 12, 43024-43031, doi: 10.1021/acsami.0c13962.

[143] G. Xiao, Y. Wang, H. Zhang, Z. Zhu and S. Fu, Int. J. Biol. Macromol., 2021, 170, 272-283, doi: 10.1016/j.ijbiomac.2020.12.156.

[144] T. Siripongpreda, B. Somchob, N. Rodthongkum and V. P. Hoven, Carbohydr. Polym., 2021, 256, 117506, doi: 10.1016/j.carbpol.2020.117506.

[145] H. Guan, J. Meng, Z. Cheng and X. Wang, ACS Appl. Mater. Interfaces, 2020, 12, 46357-46365, doi: 10.1021/acsami.0c12561.

[146] M. Hospodiuk, M. Dey, D. Sosnoski and I. T. Ozbolat, Biotechnol. Adv., 2017, 35, 217-239, doi: 10.1016/j.biotechadv.2016.12.006.

[147] C.-C. Kuo, H. Qin, Y. Cheng, X. Jiang and X. Shi, Food Hydrocolloid., 2021, 11, 106262, doi: 10.1002/cnma.201600191.

[148] F. Cheng, X. Cao, H. Li, T. Liu, X. Xie, D. Huang, S. Maharjan, H. P. Bei, A. Gomez, J. Li, H. Zhan, H. Shen, S. Liu, J. He and Y. S. Zhang, Nano Lett., 2019, 19, 3603-3611, doi: 10.1021/acs.nanolett.9b00583.

[149] D. Klemm, K. Petzold-Welcke, F. Kramer, T. Richter, V. Raddatz, W. Fried, S. Nietzsche, T. Bellmann and D. Fischer, Carbohydr. Polym., 2021, 254, 117313, doi: 10.1016/j.carbpol.2020.117313.

[150] H. G. de Oliveira Barud, R. R. da Silva, H. da Silva Barud, A. Tercjak, J. Gutierrez, W. R. Lustri, O. B. de Oliveira and S. J. L. Ribeiro, Carbohydr. Polym., 2016, 153, 406-420, doi: 10.1016/j.carbpol.2016.07.059.

[151] N. Shah, M. Ul-Islam, W. A. Khattak and J. K. Park, 
Carbohydr. Polym., 2013, 98, 1585-1598, doi: 10.1016/j.carbpol.2013.08.018.

[152] T. Maneerung, S. Tokura and R. Rujiravanit, Carbohydr. Polym., 2008, 72, 43-51, doi: 10.1016/j.carbpol.2007.07.025.

[153] L. C. S. Maria, A. L. C. Santos, P. C. Oliveira, A. S. S. Valle, H. S. Barud, Y. Messaddeq and S. J. L. Ribeiro, Polímeros, 2010, 20, 72-77, doi: 10.1590/S0104-14282010005000001.

[154] J. Guo, Z.R. Chen, W. Abdul, J. Kong, M.A. Khan, D.P. Young, J.F. Zhu, Z.H. Guo, Adv Compos. Hybrid Mater., 2021, doi: 10.1007/s42114-021-00242-z.

[155] J. Guo, X. Li, H. Liu, D.P. Young, G. Song, K.N. Song, J.F. Zhu, J. Kong, Z.H. Guo, Adv Compos. Hybrid Mater., 2021, 4, 51-64, doi: 10.1007/s42114-021-00211-6.

\section{Author information}

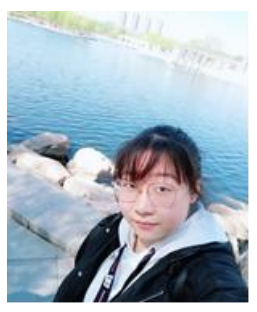

Yixuan Li is a junior student currently studying in the School of Chemistry, Chemical Engineering and Resource Utilization, Northeast Forestry University, China. Her research topics are mainly focusing on cellulose gels and flexible sensors.

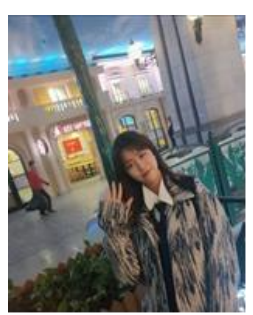

Jing Guo is currently studying chemical engineering and technology at Northeast Forestry University, China. Her current research is about cellulose gel material electronic skin and flexible sensor.

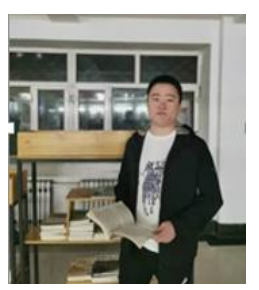

Ming Li is now studying in the third year of junior year at the School of Chemistry, Chemical Engineering and Resource Utilization, Northeast Forestry University, China. His current research focuses on the application of cellulose gel in sports equipment.

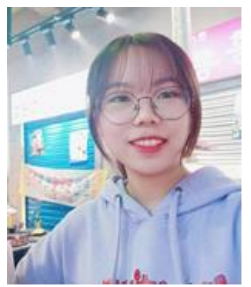

Yutong Tang is studying for her bachelor's degree in the School of Chemistry, Chemical Engineering and Resource Utilization at Northeast Forestry University, China. Her research focuses on the application of cellulosic gels in medical sensing.

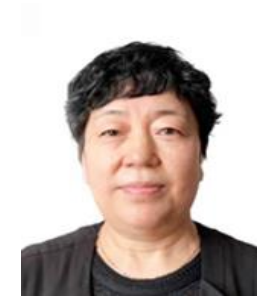

Caiying Sun is currently teaching in the College of Chemistry, Chemical Engineering and Resource Utilization at Northeast Forestry University, China. Her research interests include phosphorus based flame retardant, flexible polymer material, natural polymer material modification, etc.

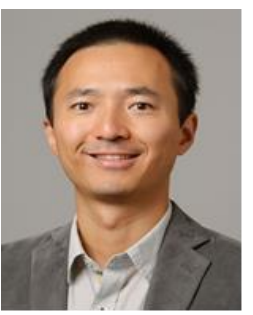

Yangchao Luo is an Associate Professor in the Department of Nutritional Sciences at the University of Connecticut. Dr. Luo's research is highly interdisciplinary and his laboratory applies materials science and engineering principles to understand physical and chemical interactions among natural biomaterials at the nanoscale and design novel nanodelivery systems for applications in food safety, quality, and functionality.

Publisher's Note: Engineered Science Publisher remains neutral with regard to jurisdictional claims in published maps and institutional affiliations. 